\title{
A Comprehensive Review of HCN-Derived Polymers
}

\author{
Marta Ruiz-Bermejo ${ }^{1, * \mathbb{D}}$, José Luis de la Fuente ${ }^{2}$, Cristina Pérez-Fernández ${ }^{1}$ and Eva Mateo-Martí ${ }^{1}$ (D) \\ 1 Centro de Astrobiología (INTA-CSIC), Dpto. Evolución Molecular, Ctra. Torrejón-Ajalvir, km 4, Torrejón de \\ Ardoz, 28850 Madrid, Spain; crisperez@cab.inta-csic.es (C.P.-F.); mateome@cab.inta-csic.es (E.M.-M.) \\ 2 Instituto Nacional de Técnica Aeroespacial “Esteban Terradas” (INTA), Ctra. Torrejón-Ajalvir, km 4, Torrejón \\ de Ardoz, 28850 Madrid, Spain; fuentegj@inta.es \\ * Correspondence: ruizbm@cab.inta-csic.es; Tel.: +34-915-206-458; Fax: +34-915-206-410
}

check for updates

Citation: Ruiz-Bermejo, M.; de la Fuente, J.L.; Pérez-Fernández, C.; Mateo-Martí, E. A Comprehensive Review of HCN-Derived Polymers. Processes 2021, 9, 597.

https://doi.org/10.3390/ pr9040597

Academic Editor: Anil K. Bhowmick

Received: 12 March 2021

Accepted: 24 March 2021

Published: 29 March 2021

Publisher's Note: MDPI stays neutral with regard to jurisdictional claims in published maps and institutional affiliations.

Copyright: (c) 2021 by the authors. Licensee MDPI, Basel, Switzerland. This article is an open access article distributed under the terms and conditions of the Creative Commons Attribution (CC BY) license (https:// creativecommons.org/licenses/by/ $4.0 /)$.

\begin{abstract}
HCN-derived polymers are a heterogeneous group of complex substances synthesized from pure $\mathrm{HCN}$; from its salts; from its oligomers, specifically its trimer and tetramer, amino-nalono-nitrile (AMN) and diamino-maleo-nitrile (DAMN), respectively; or from its hydrolysis products, such as formamide, under a wide range of experimental conditions. The characteristics and properties of $\mathrm{HCN}$-derived polymers depend directly on the synthetic conditions used for their production and, by extension, their potential applications. These puzzling systems have been known mainly in the fields of prebiotic chemistry and in studies on the origins of life and astrobiology since the first prebiotic production of adenine by Oró in the early years of the 1960s. However, the first reference regarding their possible role in prebiotic chemistry was mentioned in the 19th century by Pflüger. Currently, $\mathrm{HCN}$-derived polymers are considered keys in the formation of the first and primeval protometabolic and informational systems, and they may be among the most readily formed organic macromolecules in the solar system. In addition, $\mathrm{HCN}$-derived polymers have attracted a growing interest in materials science due to their potential biomedical applications as coatings and adhesives; they have also been proposed as valuable models for multifunctional materials with emergent properties such as semi-conductivity, ferroelectricity, catalysis and photocatalysis, and heterogeneous organo-synthesis. However, the real structures and the formation pathways of these fascinating substances have not yet been fully elucidated; several models based on either computational approaches or spectroscopic and analytical techniques have endeavored to shed light on their complete nature. In this review, a comprehensive perspective of $\mathrm{HCN}$-derived polymers is presented, taking into account all the aspects indicated above.
\end{abstract}

Keywords: HCN-derived polymers; cyanide chemistry; prebiotic chemistry; multifunctional materials; 2D materials

\section{Introduction}

HCN-derived polymers, commonly simply called HCN polymers, comprise a heterogeneous family of complex organic substances synthesized from pure HCN or soluble cyanide salts (e.g., $\mathrm{NaCN}, \mathrm{KCN}$ or $\mathrm{NH}_{4} \mathrm{CN}$ ); from the oligomers, trimers and tetramers of $\mathrm{HCN}$, including amino-nalono-nitrile (AMN) and diamino-maleo-nitrile (DAMN); or from the hydrolysis products of HCN such as formamide, under a wide range of experimental conditions. They are heterogeneous solids ranging in color from yellow or orange to brown or black depending on the degree of polymerization and/or cross-linking. A brief summary of their syntheses is shown in Scheme 1.

The HCN is a ubiquitous molecule in the Universe [1,2]. It has been detected in interstellar clouds, star-forming regions, planetary nebulae, interplanetary dust, comets [3], meteorites and atmospheres of satellites and planets such as Titan and Pluto [4-6]. In a terrestrial context, HCN can be identified in volcanic eruptions [7] and hydrothermal vents [8,9] and may have been relatively abundant in the atmosphere of the early Earth [10,11]. In addition, HCN polymers are considered the oldest organic substances of the solar system $[12,13]$. On the other hand, the synthetic story of HCN polymers began long ago. In 
the lab, $\mathrm{HCN}$ was prepared for the first time by Scheele in the second part of the 18th century by heating blood with $\mathrm{KOH}$ and charcoal. He obtained a mixture that he called "Blutlage", which he distilled with sulfuric acid [14]. A few years later, Proust observed the oligomerization of $\mathrm{HCN}$ in the early 19th century [15]. In the last part of that century, Wipperman reported his research on the conversion of aqueous HCN into its trimer (amino-malonic acid dinitrile), which was subsequently hydrolyzed and decarboxylated to produce glycine [16], and Pflüger published one of the earliest chemical speculations concerning the origin of "living proteins" from cyano compounds [17].

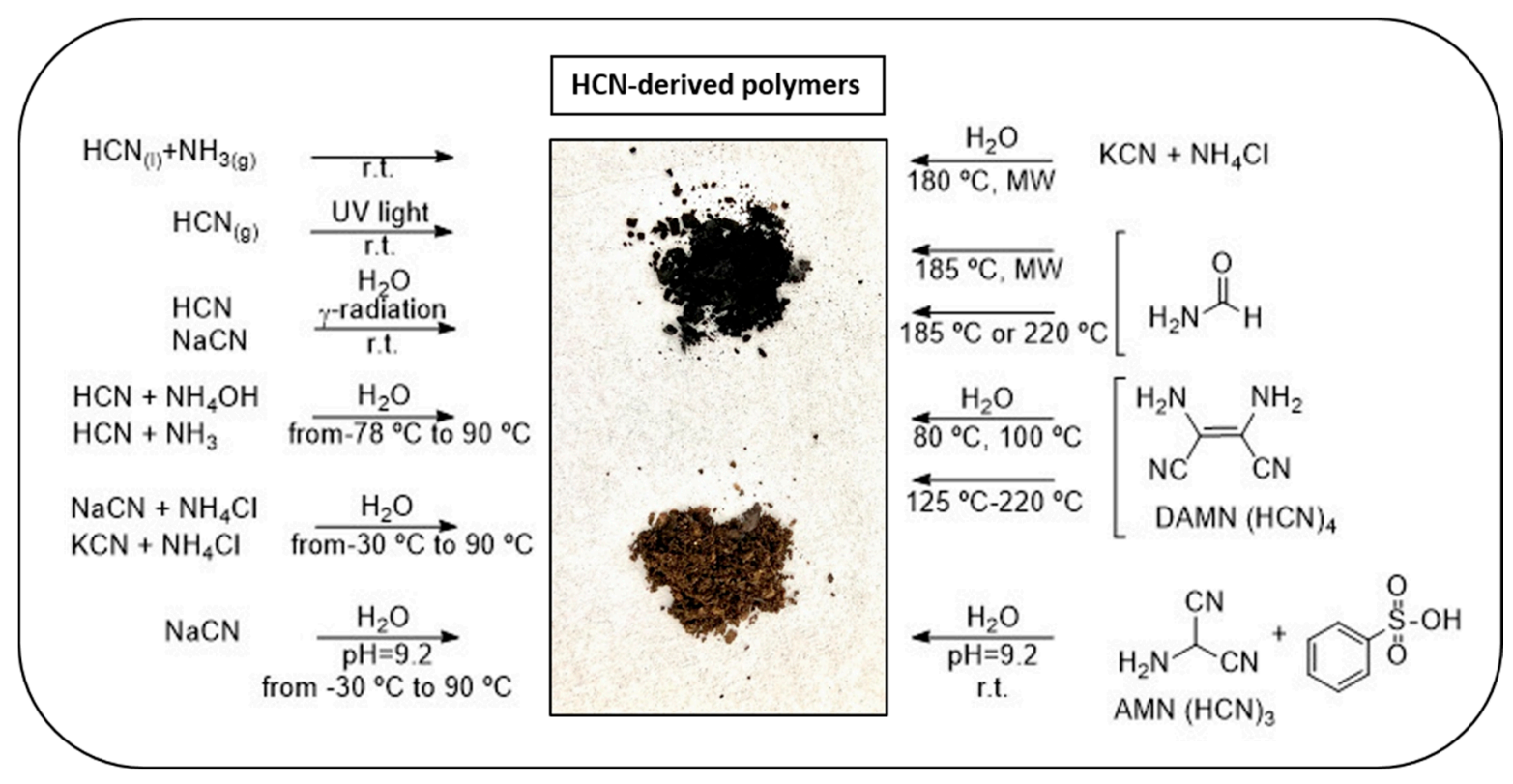

Scheme 1. Summary of the main routes for the production of HCN-derived polymers.

However, the aqueous chemistry of HCN only achieved its current importance in studies about the origin of life from the first prebiotic synthesis of adenine by Oró [18]. Since then, the reaction of HCN polymerization has generally been considered the preferential prebiotic route for the synthesis of purines and pyrimidine derivatives. Thus, it has been suggested that $\mathrm{HCN}$ polymers may be important substances in the first stages of the chemical evolution of life. Indeed, currently, HCN chemistry is considered key in new proposals regarding scenarios and hypotheses related to the first stages of increasing molecular complexity that led to the rise of life. In addition, beyond the interest in $\mathrm{HCN}$ polymers in the fields of astrochemistry, prebiotic chemistry and astrobiology, these fascinating substances are inspiring new materials and present interesting properties that can lead to promising applications. Despite their being of great interest in various fields of knowledge, the relationships between the structures and properties of $\mathrm{HCN}$-derived polymers are not sufficiently clear due to a lack of full characterization and because their properties are highly sensitive to experimental synthesis conditions. By extension, their corresponding pathways of formation are also unclear, although several structural models and hypothetical pathways have been proposed that consider both experimental data and computational analyses. All the above-mentioned aspects of these puzzling systems will be discussed within the next pages. 


\section{HCN in Prebiotic Chemistry and Astrobiology}

Currently, HCN chemistry enjoys growing attention in studies about the origin of life (Figure 1), likely due to the experimental proposals made by Sutherland's group in 2015 regarding the common origin of RNA, protein and lipid precursors in cyano-sulfidic proto-metabolism [19]. This paper, together with the conceptual approach proposed by Eschenmoser, commonly known as the "glyoxilate scenario" [20,21], suggests that the reaction networks that describe plausible protometabolic systems are based on HCN homologation, i.e., that all the carbon and nitrogen atoms contained in the compounds that are components of the reaction networks come from this unique source. In addition, Eschenmoser encouraged revisiting $\mathrm{HCN}$ chemistry by focusing on its non-robust parts to demonstrate its full potential as one of the possible roots of prebiotic self-organizing chemical processes. Moreover, very recently, aqueous HCN chemistry has again reached prominence due to computational analyses, which strongly suggest that simply $\mathrm{HCN}$ and water may be the precursors of RNA and proteins [22].

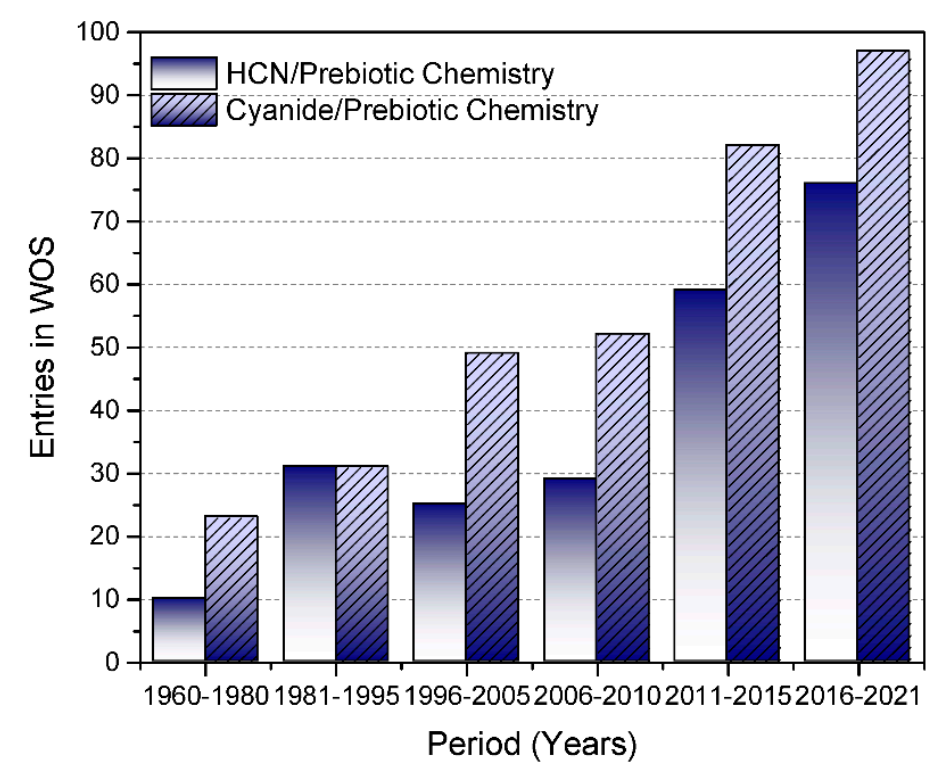

Figure 1. Number of entries provided by the Web of Science (WOS) database from 1960 to the present when performing a search with the keywords "HCN AND prebiotic chemistry" or "cyanide AND prebiotic chemistry". In the first case, there are a total of 229 entries, and there are 335 entries in the second case (as of 18 February 2021). This figure clearly shows the growing interest in cyanide chemistry in studies about the origin of life over the years.

As indicated above, the oligomerization/polymerization of cyanide has thus far been considered the preferential prebiotic route for the production of nucleobases, including both purines and pyrimidines (see, e.g., $[23,24])$. In this sense, nucleobases are especially relevant to the experimental works by Ferris et al. in the 1960s and 1970s [25-31], the reports by Schwartz et al. in the following decade [32-37] and, more recently, the research of Miller's group [38,39]. Additionally, several computational works have focused on the possible prebiotic production of nucleobases from $\mathrm{HCN}$ while taking into account several scenarios (atmospheric, interstellar or aqueous) [40-42]. In addition, it is well known that the oligomerization/polymerization of HCN leads to the production of amino acids and hydantoins after hydrolysis [39,43-49]. In this sense, the constructive and high-level scientific replicates between Ferris and Matthews about the peptide nature of HCN polymers in the last years of the 1970s and 1980s are notable and will be discussed below. Moreover, the aqueous oligomerization of $\mathrm{HCN}$ generates precursors of co-factors such as pteridines [50] and carboxylic acids (some of which are implicated in the reductive tricarboxylic acid cycle or inverse Krebs cycle) [51], fatty acids [45], and other compounds such as triazines, which are considered non-canonical nucleobases in the informational polymers of a plausible 
"pre-RNA world" [51,52]. On the other hand, the radiolysis of aqueous HCN solutions also gives the formation of several polar organic compounds of biological interest [53-55]. In addition, recently, the synthesis of RNA precursors such as glyco-aldehyde, cyanamide, 2-aminooxazole and 2-aminoimidazole has been demonstrated from HCN by combining radiolysis and dry-down techniques [56]. Additionally, it is possible to produce simple sugars from an excess of $\mathrm{HCN}$ in the presence of $\mathrm{e}^{-}$aq [57-59]. Thus, the HCN molecule is considered a main compound in the chemical evolution processes that lead to the generation of protometabolic and informational systems in the development of primitive biochemistry [60] (Figure 2).

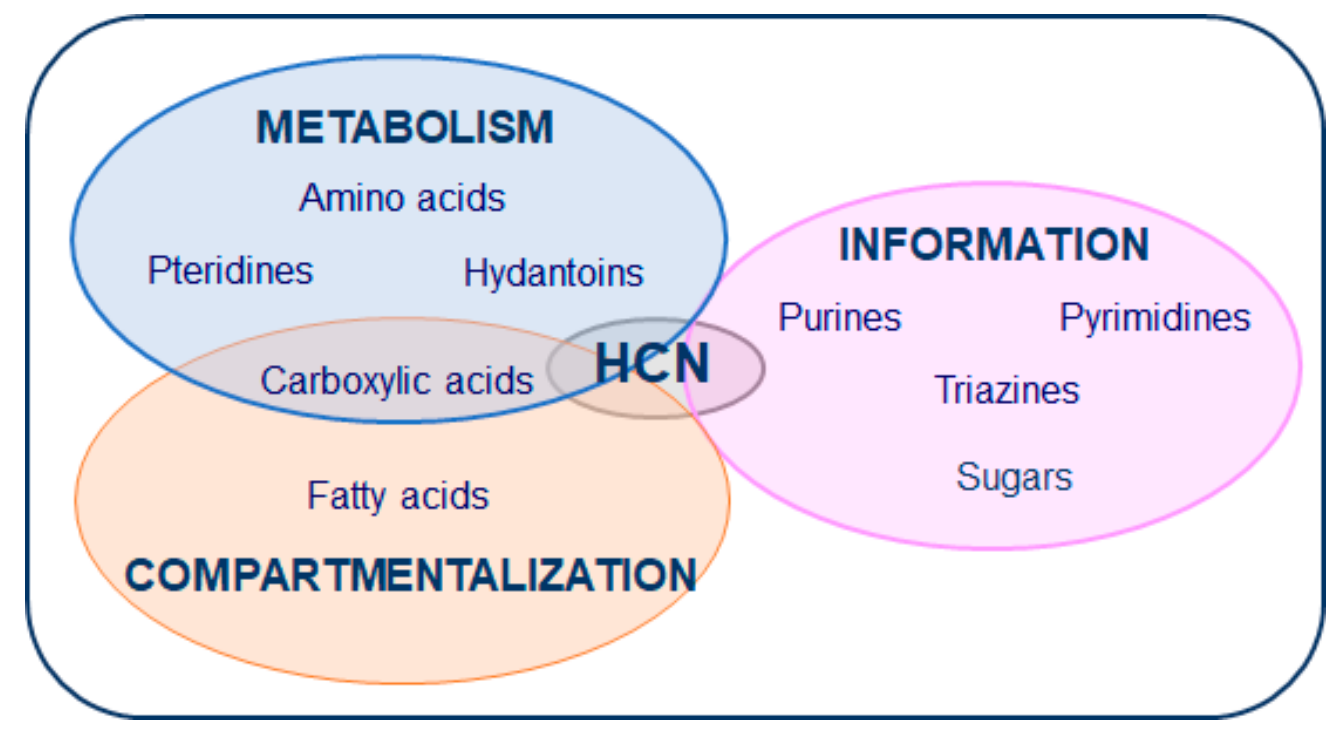

Figure 2. $\mathrm{HCN}$ is a key molecule in the simultaneous development of primaeval protometabolic, informational and compartmentalization systems.

At this point, it should be pointed out that HCN only efficiently oligomerizes/ polymerizes in aqueous environments at alkaline $\mathrm{pH}$ values, preferably between $\mathrm{pH}=8$ and $\mathrm{pH}=10$ [61]. Therefore, from a prebiotic point of view, aqueous $\mathrm{HCN}$ polymerization can be reduced to cyanide polymerization because the $\mathrm{pK}_{\mathrm{a}}$ of $\mathrm{HCN}$ is 9.2 , and most of the prebiotic syntheses indicated above were carried out at $\mathrm{pH}$ values higher than or equal to 9.2. In any case, concentrations greater than $0.01 \mathrm{M}$ are required for $\mathrm{HCN}$ to oligomerize/polymerize in aqueous solutions, whereas in more dilute solutions hydrolysis is the dominant process [26]. Therefore, taking into consideration the issue of the possible $\mathrm{HCN}$ concentrations in aqueous natural environments, the following question arises: was the oligomerization/polymerization of $\mathrm{HCN}$ possible on primitive Earth? Some recent studies have proposed possible formation mechanisms and concentration ranges for HCN in the early Earth's atmosphere, both at the planetary level and in local environments [10,11,62-65].

On the other hand, the presence of HCN in hydrothermal systems has been suggested in both submarine [8,9] and, more recently, aerial $[66,67]$ hydrothermal vents. Although the solubility of $\mathrm{HCN}$ in water is high, its rates of formation on the early Earth, in any possible scenario, would not achieve the concentration necessary for efficient oligomerization/polymerization. Therefore, if the aqueous chemistry of $\mathrm{HCN}$ was truly important for the production of the first organic molecules essential for the later development of primitive biochemistry, there must have been effective mechanisms for the concentration of the cyanide ion. Because $\mathrm{HCN}$ is more volatile than water (i.e., boiling point of $25.6^{\circ} \mathrm{C}$ ), it cannot be concentrated by evaporation if the $\mathrm{pH}$ is lower than the $\mathrm{pK}_{\mathrm{a}}$ of $\mathrm{HCN}$. Considering the synthetic restrictions imposed by prebiotic chemistry on the early Earth, the following possible mechanisms for the concentration of cyanide are postulated: (i) cooling at the eutectic point; (ii) evaporation in local environments with high $\mathrm{pH}$ values; (iii) precipitation 
and/or concentration in the form of ferrocyanides; (iv) concentration in microenvironments such as mineral surfaces; and v) floating patches at the water surface.

The eutectic phase of an aqueous HCN solution, which occurs at $-23.4{ }^{\circ} \mathrm{C}$, contains $74.5 \% \mathrm{HCN}(25 \mathrm{M})$ [26]. In the context of the early Earth, glaciers can be proposed as more favourable sites for $\mathrm{HCN}$ oligomerization/polymerization because eutectic formation requires complete freezing. In the solar system, ice moons such as Europa and Enceladus are also relevant in this regard considering their frozen aqueous layers as concentrators of HCN likely to have been produced in their liquid subsurface oceans, which have hydrothermal activity. Thus, the polymerization of $\mathrm{HCN}$ under frozen conditions has been explored, and several organics, mainly N-heterocycles, have been detected after hydrolysis of the HCN oligomers/polymers obtained using these kinds of synthesis $[32,38,39,68]$.

The discovery of alkaline lakes on modern Earth, with $\mathrm{pH}$ values between 9 and 12 (see, e.g., [69-71]), presents a new possibility for the concentration of cyanide by evaporation [72]. Especially interesting is the recently reported oligomerization/polymerization of $\mathrm{HCN}$ under thermolysis conditions in alkaline environments, leading to an increase in the molecular complexity of $\mathrm{HCN}[73,74]$.

It has been recently proposed that high concentrations of ferrocyanide would have been possible on the early Earth over wide ranges of temperatures and partial pressures of $\mathrm{CO}_{2}$ and HCN. Ferrocyanide salts may have formed in endorheic basin lakes rich in $\mathrm{NaHCO}_{3}$, which may have been common on the early Earth due to the high concentration of atmospheric $\mathrm{CO}_{2}$ and active volcanism [72]. Previously, a geological scenario was proposed in evaporitic basins wherein the concentrations of ferrocyanides and other salts would be possible; in this scenario, ferrocyanides could act as a means to obtain concentrated cyanide solutions [19]. The production of ferrocyanides under plausible prebiotic conditions has been demonstrated experimentally [75], and their presence has also been reported in volcanic hydrothermal environments in the Kuril Islands [76,77]. The production of amino acids has been tested successfully using several ferrocyanides as cyanide sources under plausible prebiotic Strecker syntheses [78,79], and thermal decomposition under the alkaline conditions of Prussian Blue, $\mathrm{Fe}^{\mathrm{III}} 4\left(\mathrm{Fe}^{\mathrm{II}}(\mathrm{CN})_{6}\right)_{3} 15 \mathrm{H}_{2} \mathrm{O}$, leads to the generation of hematite, $\alpha$ - $\mathrm{Fe}^{\mathrm{III}}{ }_{2} \mathrm{O}_{3}$, the complex soluble salt $\left(\mathrm{NH}_{4}\right)_{4}\left(\mathrm{Fe}^{\mathrm{II}}\left(\mathrm{CN}_{6}\right)\right) \cdot 1.5 \mathrm{H}_{2} \mathrm{O}$ and several organic compounds, such as urea, lactic acid, 5,5-dimethylhydantoin, a set of amino and carboxylic acids, and free HCN, cyanogen and formamide [80]. Studies on the absorption of ribonucleotides over Prussian Blue nanoparticles have been carried out [81]. Indeed, it has recently been proven that cyanide and some of its derivatives (Prussian Blue, urea, ammonium formiate and formamide) are keys in the phosphorylation of nucleosides [82].

It has been demonstrated that double-layered hydroxides catalyze the self-addition of cyanide even down to $0.01 \mathrm{M}$ cyanide concentrations to yield DAMN [83] and that specific sites on the surface of sodium montmorillonite increase the concentration of HCN molecules dependent on the $\mathrm{pH}$ values [84]. However, other studies have focused on the role of this mineral in the oligomerization/polymerization of cyanide, finding that the formation of HCN oligomers is strongly inhibited by montmorillonite clays [85], likely to be due to the oxidation process undergone by DAMN to form di-imino-succino-nitrile (DISN) in the presence of these minerals [86]. In this line of work, it was also shown that the radiolysis of $\mathrm{HCN}$ in the presence of Na-montmorillonite led to the formation of carboxylic acids, though to a lesser extent than that determined in a control experiment without minerals [55].

Finally, it has been proposed that aqueous interfaces could play an important role in chemical evolution processes $[87,88]$. Thus, regarding HCN chemistry, the HCN molecule can undergo strong interfacial adsorption at the surfaces of aqueous solutions, forming floating $\mathrm{HCN}$ patches that can provide excellent spots for polymerization, especially at small concentrations [89]. Beyond this result, it is necessary to mention the role of the aqueous interfaces, the air-liquid water and ice-liquid water interfaces, in the production of glyoxylic acid, the main reactant in the abovementioned "glyoxilate scenario". The presence of aqueous aerosols and freeze-thaw cycles significantly favors the formation 
of glyoxylic acid from cyanide [51,68]. Additionally, water-air interfaces assist in the hydrocyanic production of co-factors such as pteridines [50].

In any case, considering the available mechanisms of HCN concentration in the early Earth, $\mathrm{HCN}$ chemistry and the extension of $\mathrm{HCN}$ polymers in the first steps of chemical evolution towards increasing organic molecular complexity seem sufficiently important.

However, what happens in an extra-terrestrial context? Is it possible to develop rich organic chemistry from $\mathrm{HCN}$ ? The response seems to be positive. $\mathrm{HCN}$ polymers have been proposed to be the major components of the dark matter observed on many bodies of the solar system and beyond, including asteroids, moons, planets and, especially, comets [90,91], linking cosmochemistry with primitive terrestrial biochemistry [92]. It has been proposed that the main source of the $\mathrm{CN}$ observed in comets may be $\mathrm{HCN}$ polymers [93]. Thus, HCN polymers could have been important exogenous sources of organic material in the early Earth during the late heavy bombardment in the Hadean eon. Experimentally, possible analogies between cometary nitrogen-rich refractory organics and the thermal degradation products of $\mathrm{HCN}$ polymers have been identified in research [94]. In addition, some calculations estimate that comet impacts on the early Earth could have provided prebiotically interesting HCN levels for thousands to millions of years [95], and the presence of iron cyano-carbonyl, $\left(\mathrm{Fe}(\mathrm{CN})_{5}(\mathrm{CO})\right)^{-3}$ and $\left(\mathrm{Fe}(\mathrm{CN})_{4}(\mathrm{CO})_{2}\right)$, in some meteorites such as Lewis Cliff 85,311 has been reported; these complexes may deliver significant quantities of cyanide after the appropriate geochemical processes have occurred [96]. Additionally, activation by an impact plasma simulated in high-velocity impacts on the early Earth, including a reducing atmosphere $\left(\mathrm{CO}, \mathrm{CH}_{4}\right.$ and $\left.\mathrm{N}_{2}\right)$, leads to the production of all RNA nucleobases and the protein amino acid glycine, with $\mathrm{HCN}$ being the first precursor generated in this one-pot synthesis [97]. Therefore, HCN, or HCN polymers, are not only endogenous sources for primitive biochemistry but are also plausible exogenous extra-terrestrial sources.

On the other hand, measurements from the Cassini-Huygens mission of the atmosphere and the surface of Saturn's moon Titan suggest that HCN-based polymers may have formed on the surface of Titan from products of atmospheric chemistry. Indeed, the observations from Cassini/VIMS confirm a seasonal variation in the HCN volume mixing ratio in the upper atmosphere of Titan [98]. This makes Titan a valuable "natural laboratory" for exploring potential non-terrestrial forms of prebiotic chemistry. Thus, the chemical transitions from simple molecules such as $\mathrm{HCN}$ into aerosol particles have been investigated using a one-dimensional photochemical model of Titan's atmosphere [99] together with the optical properties of the molecules [100], the presence of free radicals [101], mass spectra [102], polymorphism and the electronic structure [103] of different HCN polymers synthesized under several conditions and compared with simulated tholins on Titan or with observational data. Moreover, the theoretical properties of a ternary benzene/acetylene/hydrogen cyanide co-crystal have been predicted due to its likely implications for the solid-state formation of complex organics in Titan's atmosphere [104]. On another of Saturn's moons, such as Iapetus, the organic matter detected in its leading hemisphere might be partially composed of HCN polymers [105]. Phoebe, which could be a primitive Kuiper belt object, contains significant amounts of HCN-like polymers [106]. Taking in mind an extra-terrestrial origin of life and the discovery of cyano-methanimine and $\mathrm{AMN}$, the dimer and the trimer of $\mathrm{HCN}$, respectively, in star-forming regions, a theoretical investigation of proton collisions with these species was performed to determine their stability against UV radiation and ion collisions via the modelling of several astrophysical environments [1]. The formation of RNA and DNA nucleobases was also found to be possible from HCN through a free radical pathway either under a meteoritic impact scenario on the early Earth or in the gas phases of interstellar regions [107]. The production of $\mathrm{HCN}$ may also be possible in rocky exoplanets with nitrogen-rich atmospheres, expanding the possibilities of finding complex organic chemistry beyond the solar system [108]. In addition, the photolysis and irradiation of astrophysical ice analogues containing HCN have been studied, showing that pure $\mathrm{HCN}$ seems to be polymerized by incident radiation, 
which would indicate rich $\mathrm{HCN}$ chemistry in icy mixtures of interstellar medium (ISM) or in comets where $\mathrm{HCN}$ is available [109].

Although beyond the scope of this review, studies on the roles of formamide and urea, derivatives of $\mathrm{HCN}$, in the first steps of the origins of life are also of high interest. Formamide condenses at high temperatures in the presence of several inorganic catalysts, donating a notable amount of key bioorganic molecules [110], even in thermolysis experiments lacking these catalysts. [111]. Concentrated solutions of urea under the constraints of prebiotic chemistry also led to the production of a notable number of $\mathrm{N}$-heterocycles, such as triazines and pyrimidines [112,113].

\section{Promising Applications in Materials Science}

As discussed above, there is a well-established research line driving the role of $\mathrm{HCN}$ in chemical evolution processes from inorganic chemistry to primitive biology. Beyond this prebiotic approach to $\mathrm{HCN}$ chemistry, $\mathrm{HCN}$ polymers have recently received growing attention in the fields of materials and surface science towards the development of multifunctional systems [114] (Figure 3).

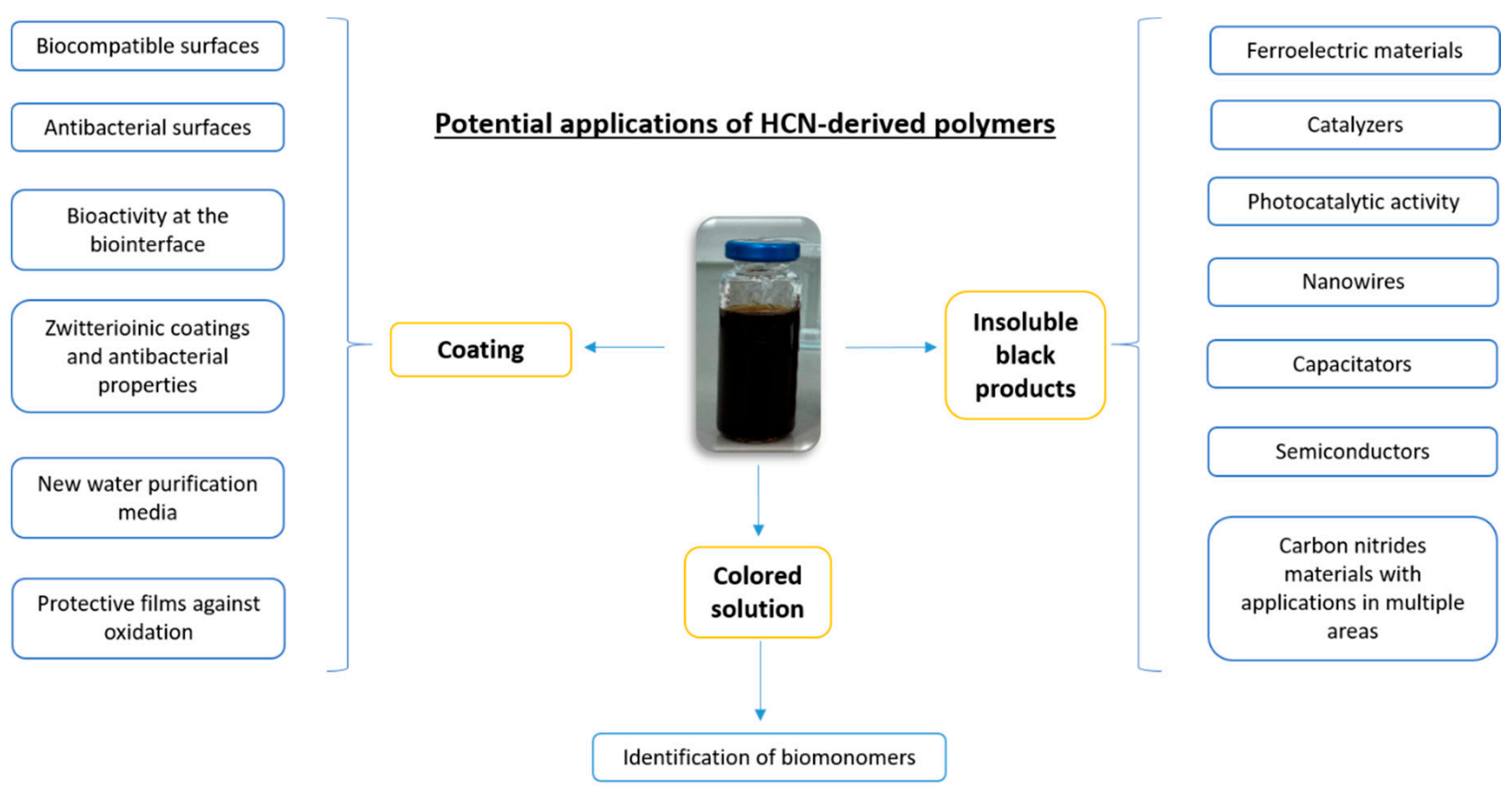

Figure 3. Current stage of the potential applications of HCN-derived polymers. The properties of HCN-derived polymers are directly dependent on the synthetic experimental conditions as well as on the chosen phase from the whole polymerization.

During the aqueous polymerization of $\mathrm{HCN}$, cyanide, AMN or DAMN can often be observed in three phases from the reaction medium: (i) a colored solution from yellow to dark brown; (ii) an insoluble black residue that can be collected by filtration or centrifugation; and (iii) a film deposited on the reaction vessel wall. Traditionally, in the field of prebiotic chemistry, the main focus has been the study of solutions for the identification of bio-monomers and related compounds by chromatography and spectroscopy techniques. The insoluble black residues have been analysed under this point of view due to the likely similar nature of the HCN polymers and Titan's tholins. In this line, as briefly discussed above, the polymorphism and electronic structure of poly-imines have been investigated for their potential impacts on the understanding of the prebiotic chemistry of Titan [103] since $\mathrm{He}$ et al. showed that $75 \%$ of an $\mathrm{HCN}$-based polymer formed in laboratory experiments consisted of a poly-imine [115]. Due to the characteristics found for this poly-imine, consisting formally of hydrogen isocyanide units, it was proposed as a valuable model for functional material design, such as for ferroelectric materials, nanowires, semiconductors 
and catalysts [103]. Moreover, nano-fibers of poly-hydrogen cyanide synthesized from the heating of formamide present photocatalytic activities [116], and some DAMN polymers might be used as capacitators [117]. On the other hand, $\mathrm{NH}_{4} \mathrm{CN}$ and the DAMN polymers described recently present structural features very similar to those of extensively studied carbon nitrides $[52,117,118]$, which are known to be used as materials with applications in multiple areas [119].

Finally, the films were properly studied for their potential biomedical applications. The most extensively investigated films are the AMN-based film coatings [120]. AMN spontaneously polymerizes yielding coatings similar to polydopamine coatings, providing biocompatible surfaces [121]. Recent studies have demonstrated that water solutions of AMN produce adhesive coatings that can be deposited on a wide range of substrates and provide excellent cell attachment as well as the ability to bind metals for the generation of antibacterial surfaces [122,123]. The copolymerization of AMN with 3,4-di- and 3,4,5-trihydroxybenzaldehyde leads to the production of bone-contacting medical devices with excellent bioactivity at the bio-interfaces [124]. The copolymerization of AMN with sulfo-betaine methacrylate and 2-aminoethyl methacrylate via free radicals forms zwitterionic coatings, which reduce biofouling and foreign body responses [125] and also have antibacterial properties [126]. In this line of antimicrobial activity, zeolite substrates were coated with copolymers based on AMN and 3,4,5-trihydroxybenzaldehyde for the passive ultrafiltration of stormwater/greywater, providing new water purification media [127]. Moreover, the antioxidant activities of films obtained based on AMN polymers have been recently reported [128].

\section{Characterization and Kinetic Analyses of HCN-Derived Polymers: Dependence of the Properties on Synthetic Conditions}

The potential applications of a new material depend directly on their properties, which are generally derived from synthetic parameters. Considering that polymer properties are controlled by molecular features, such as the molecular weight (MW), molecular distribution, chemical composition, stereochemical distribution of the copolymer chain, and degree of cross-linking, summaries of these features and others will be shown in this section. The chemistry of HCN offers significant relevant opportunities for practical exploitation because of the ease of its production and the scope of the tuning materials and properties that can be obtained through the reaction conditions used and the choice of monomers, as will be discussed below.

\subsection{Molecular Weight}

HCN polymers may contain structures with broad molecular weight distributions (MWDs) [129]. However, few examples have been reported regarding this topic, i.e., studies of the MWDs of HCN polymers are limited. In pioneering works, Ferris et al. studied soluble fractions from water solutions of $\mathrm{HCN}(0.1 \mathrm{M})$ at $\mathrm{pH}=9.2$ (adjusted with $\mathrm{NH}_{4} \mathrm{OH}$ ) maintained at room temperature for one to six months using paper electrophoresis and gel filtration experiments (Sephadex G-25 and Bio-gel P2 columns). They concluded that no polymers formed, and only oligomeric materials with a maximum MW of 700 uma were achieved [130]. Mizutani and co-workers carried out the photochemical decomposition of net HCN using a vacuum lamp of mercury (the UV light that was emitted was mostly composed of two resonance lines at 184.9 and $253.7 \mathrm{~nm}$ ). The final product of the reaction was a mixture of various fractions with estimated MWs ranging from 100 to 2000 uma obtained using a gel column of polystyrene [131]. More recently, oxygen-free aqueous solutions of $\mathrm{NH}_{4} \mathrm{CN}(0.1 \mathrm{M}, \mathrm{pH}=9)$ were exposed to gamma rays from a ${ }^{60}$ Co source; the mixture of non-volatile products was fractionated, the fractions were analysed by gel filtration using Sephadex G-25, G-15, and G-15-HC1 columns, and the MWs were estimated to be between 1600 and 5000 uma [132]. The irradiation of the water solution of HCN $(0.1 \mathrm{M}$ at $\mathrm{pH}=6)$ with a radiative source of cobalt at $17^{\circ} \mathrm{C}$ using several radiation doses led to the identification of different soluble fractions with MWs between 1500 and 20,000 uma, as determined by gel filtration and dialysis [133]. In addition, a polymer with a molecular 
mass of 16,000 uma was found when $\mathrm{HCN}(\mathrm{pH}=6)$ and $\mathrm{NH}_{4} \mathrm{CN}(\mathrm{pH}=9.2)$ water solutions were irradiated. The abundance of these polymers increased with the initial cyanide concentration (in a range from $0.001 \mathrm{M}$ to $0.1 \mathrm{M}$ ) and absorbed dose and were found to be up to $31 \%$ of the total amount of radiolytic products. Chromatographic data, using a micro-Pak TSK G-2000 SW column, also indicated the presence of two more products at 22,000 uma and 1000 uma that were less abundant by one order of magnitude [134].

In contrast, a more recent paper showed the formation of fractions with electrophoretic mobility with apparent MWs in a range from 16,000 to 140,000 uma obtained from the polymerization reaction of cyanide $(1 \mathrm{M})$ in water at room temperature $(\mathrm{pH}=9.2-9.5)$. These MWs were determined by bidimensional electrophoresis, and in this case, the use of ultrafiltration techniques revealed the identification of soluble fractions with MWs above 30,000 uma in all the samples studied. The statistical analyses of the electrophoresis and ultrafiltration data from all samples synthetized under different conditions in this particular study indicated that the presence of air and ammonium has a significant influence on the polymerization processes [135]. In addition, the cyanide polymers obtained in the experiments conducted in the absence of oxygen were fractionated by native gel electrophoresis, and no substantial differences were observed from the tricine-SDS electrophoresis fractionation. Therefore, macromolecular fractions with electrophoretic mobility may be highly charged and unfolded. This result is consistent with the failures of previously reported attempts as well as our own attempt to record the mass spectra of HCN polymers. Due to their very high MWs and the likely presence of high numbers of charges in their structures, the heterogeneous nature of these complex substances hinders the recording of their mass spectra. However, some studies have sought to characterize HCN polymers by high-resolution mass spectrometry [102,136]; in these studies, HCN polymers were synthesized in the absence of water, and the mass range studied was $\mathrm{m} / \mathrm{z}=50-1000$.

\subsection{Chemical Composition}

Table 1 shows significant examples of molar relationships obtained from several insoluble HCN polymers synthesized under different conditions. Note that these relationships are directly dependent on the polymerization parameters. However, no direct correspondence is observed between the reaction conditions and the empirical formulas. For example, for polymers with a minor oxygen content based on their $\mathrm{C} / \mathrm{O}$ ratio, entry 15 , the empirical formula is $\mathrm{C}_{4} \mathrm{H}_{4} \mathrm{~N}_{3} \mathrm{O}$, indicating a highly conjugated structure, while for $\mathrm{HCN}$-derived polymers with a minor $\mathrm{C} / \mathrm{O}$ ratio, entry 29 , a less conjugated empirical formula, $\mathrm{C}_{3} \mathrm{H}_{4} \mathrm{NO}_{5}$, can be achieved. In the first case, the reaction was carried out using a long reaction time and a relatively high temperature in the presence of air; in the second case, the temperature was high, but the reaction time was minor, and no oxygen was present in the reaction vessel. Based on the $\mathrm{C} / \mathrm{H}$ ratio, the polymer corresponding to entry 21 may be the most conjugated system; in this case, the empirical formula would be $\mathrm{C}_{7} \mathrm{H}_{9} \mathrm{~N}_{6} \mathrm{O}$, in contrast to the minor C/H ratio, again shown by entry 29 .

To conclude, the polymer from entry 15 presents a high $\mathrm{N} / \mathrm{O}$ ratio, which can be related to the denitrogenation/dehydrocyanation and hydrolysis processes that occur during the polymerization processes, as will be discussed later; the polymer from entry 29 presents a minor $\mathrm{N} / \mathrm{O}$ ratio, as expected, since it is the most oxidized polymer ever described. In any case, the percentages of oxygen determined in these samples are independent of the presence of oxygen or air during the polymerizations. The presence of oxygen in the polymers comes from water, although air has a significant influence on the kinetics of the polymerization, as will be discussed later. Taking into consideration the data collected in this table, it seems sufficiently difficult to design synthetic conditions to obtain HCN-derived polymers with a desired composition. In this way, systematic studies have been carried out recently to determine the relationship between the compositions of final $\mathrm{HCN}$-derived polymers and the reaction time, temperature and reactants, not only for insoluble polymers [52,117,128,137], but also for the compositions of coatings [138]. In 
addition, the last entries of Table 1, entries 31 and 32, illustrate two of the scarce examples of polymerization in the absence of water.

\subsection{Morphology}

The morphology and textural properties of HCN-derived polymers appear to be notably influenced by the chosen synthetic conditions and the selected starting reactant $[52,117,122,138]$. For example, Figure 4 shows representative SEM images of precipitated powder samples of $\mathrm{NH}_{4} \mathrm{CN}$ and DAMN polymers synthesized using conventional heating or using a microwave reactor. For the $\mathrm{NH}_{4} \mathrm{CN}$ polymers synthesized at $80{ }^{\circ} \mathrm{C}$ (Figure 4a), at least three types of particles with different morphologies can be described: spherical particles, flat oval particles and particles with irregular shapes and non-uniform sizes, which seemed to be aggregates of other smaller particles. However, the shapes of the DAMN polymer particles obtained under similar conditions present a well-defined stacked sheet structure (Figure 4 b).
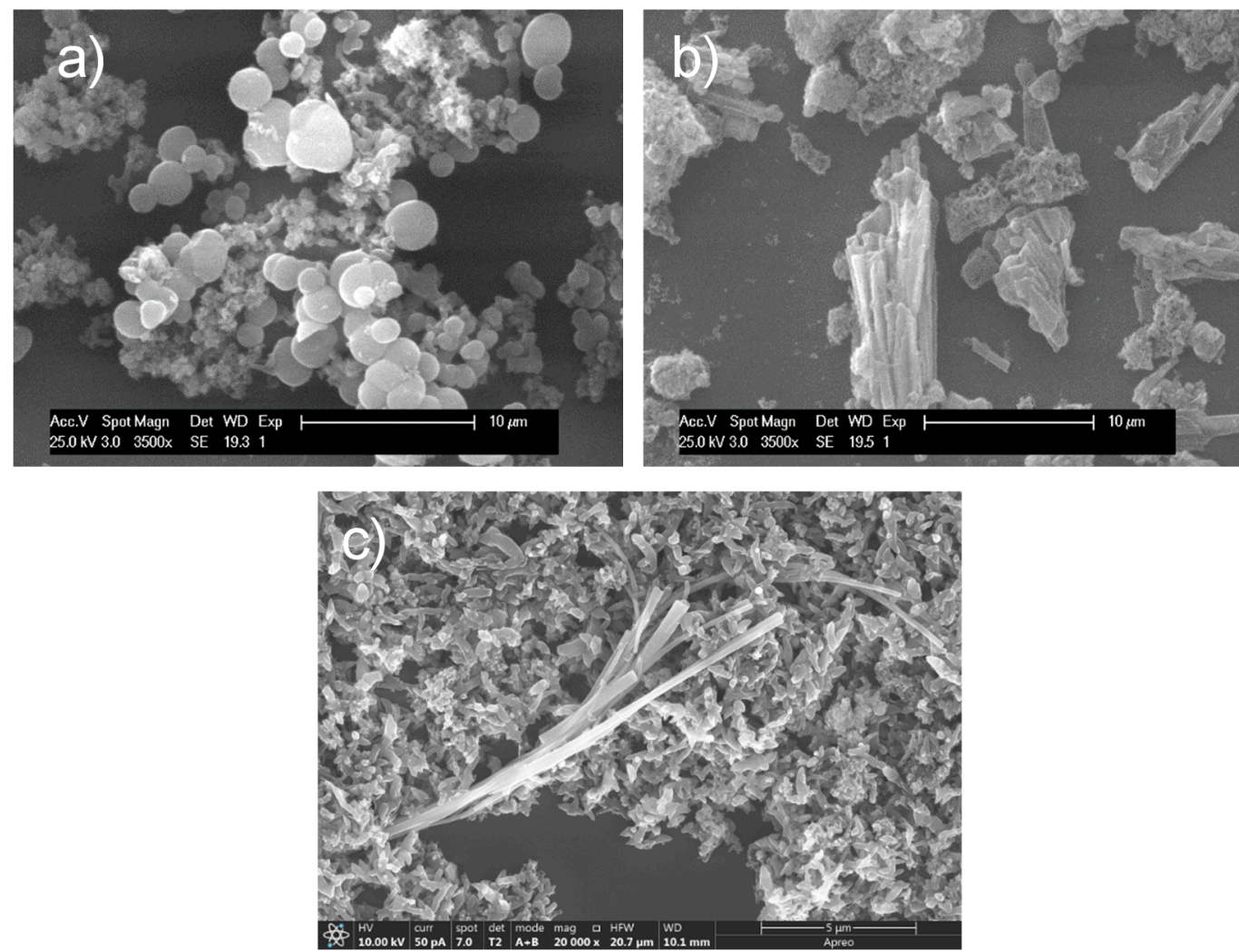

Figure 4. Insoluble $\mathrm{HCN}$-derived polymers obtained using different synthetic aqueous conditions: (a) $\mathrm{NH}_{4} \mathrm{CN}(1 \mathrm{M}), 80{ }^{\circ} \mathrm{C}$, $96 \mathrm{~h}$; (b) DAMN (0.25 M), $80^{\circ} \mathrm{C}, 48 \mathrm{~h}$; (c) $\mathrm{NH}_{4} \mathrm{CN}(1 \mathrm{M}), 180^{\circ} \mathrm{C}, 15 \mathrm{~min}$ using a microwave reactor.

In contrast, the polymerization assisted by microwave irradiation yields long nanofibers and a set of nanoparticle rice shapes (Figure $4 \mathrm{c}$ ), which are very different in contour and size with respect to the analogous $\mathrm{NH}_{4} \mathrm{CN}$ polymers synthesized using classical heating (Figure 4a). In addition, other types of nano-fibers have been identified among the $\mathrm{HCN}$-derived polymers from the heating of formamide at $200{ }^{\circ} \mathrm{C}$, but these are no longer found [116]. The generation of HCN-derived nano-fibers is interesting due their potential applications in several areas, such as tissue engineering, drug delivery, cancer diagnosis, lithium-air batteries, optical sensors, air filtration and sportswear textiles. The $\mathrm{NH}_{4} \mathrm{CN}$ polymeric nanoparticles identified here may be incorporated as novel fillers to develop composite materials [117]. However, not only insoluble HCN-derived polymers but also HCN-based coatings present morphological differences. Thus, the spontaneous aqueous 
polymerization of AMN leads to the formation of HCN-based coating films whose final morphologies depend on the coated material and deposition time [122,138]. Under these conditions, the shape of the coatings can change from spheres to net nano-fibers.

\subsection{Thermal Stability and Fourier Transform Infrared (FT-IR) Spectroscopy}

All the HCN-derived polymers reported in the bibliography present three thermal degradation stages during heating under an inert atmosphere (Figure 5a) [74,117,139-142]. (i) A drying state occurs at $<150{ }^{\circ} \mathrm{C}$ that can correspond to the vaporization of moisture, to the desorption of water and to the emission of volatile organic compounds, such as urea. This first step of weight loss at low temperature is related to the hydrophilicity of these polymers, and the loss of water is estimated to range from $2-10 \%$. (ii) A main pyrolysis stage occurs at $150-500{ }^{\circ} \mathrm{C}$. At this second stage, two zones can be differentiated. The first zone, from 150 to $300{ }^{\circ} \mathrm{C}$, is assigned to the "primary scissions" in the thermal decomposition of more thermally labile structures. In this region, the desorption of strongly retained compounds can also take place. The second zone, which occurs from 300 to $550^{\circ} \mathrm{C}$, is related to "secondary scissions" in the thermal decomposition of relatively high-stability structures. Weight losses from $25-50 \%$ are suffered in this stage. (iii) The final carbonization stage, occurring from $550-1000{ }^{\circ} \mathrm{C}$, is related to the breaking of the main chains. In this zone, char-forming reactions are dominant, yielding a char percentage from $12-27 \%$, with the exception of an $\mathrm{HCONH}_{2}$ polymer that presents a higher percentage of char, at $36 \%$ [142]. This percentage is associated with extremely thermally stable components or components that have been generated by heating to finally yield char combustion products. In addition, it has been proposed that thermal stability is directly dependent on a higher oxygen content in the HCN-derived polymer macrostructure. For example, samples 1 and 4 shown in Figure 5a (black line and blue line, respectively) are the samples with the highest $\mathrm{O} \%$ ever reported, presenting well-defined decomposition peaks at approximately $900{ }^{\circ} \mathrm{C}[74,140]$. These high oxygen contents may come from hydrolysis reactions that occur during the polymerization processes that may lead to the generation of extensive cross-linking structures by the formation of intermolecular and intramolecular amide bonds [140].

On the other hand, the possibility of extending N-heterocyclic structures cannot be ruled out to explain this stability. Moreover, the differential thermogravimetry (DTG) curves (and their respective deconvolutions, which show quite complex thermal degradation processes) provide excellent fingerprints for the differentiation of $\mathrm{HCN}$-derived polymers with very similar FT-IR spectra (Figure $5 b$ ). In general, a HCN-derived polymer spectrum can be divided into three main regions, region I $\left(3700-2500 \mathrm{~cm}^{-1}\right)$, region II (2275-2000 $\left.\mathrm{cm}^{-1}\right)$, and region III (1900-1000 $\left.\mathrm{cm}^{-1}\right)$, and into a not-well-defined region IV centered at $\sim 600 \mathrm{~cm}^{-1}$. These regions are also observed in AMN-based coatings [124]. In $\mathrm{HCONH}_{2}$, thermally derived polymers are also observed with the exception of the band centered at approximately $2200 \mathrm{~cm}^{-1}[116,142]$. Region I contains spectral features due to the symmetric and antisymmetric vibrational stretching modes of primary and secondary amine functional groups wherein the hydroxyl groups and $\mathrm{C}-\mathrm{H}$ stretching in aromatic and unsaturated hydrocarbons may overlap. In region II, the absorption band at $2200 \mathrm{~cm}^{-1}$ is associated with cyanide functional groups. The position, multiplicity and strength of this feature can vary from one sample to another sample prepared under different conditions [100]. For example, it has been observed that the diminution of the intensity of the $\mathrm{CN}$ band may occur when a $\mathrm{HCN}$ polymer has been in contact with water vapor in moist air [143], as this condition causes oxygen to be incorporated into the polymer [144]. Spectral region III exhibits spectral features that may be related to $\mathrm{C}=\mathrm{N}$ groups, such as imines $\left(\sim 1650 \mathrm{~cm}^{-1}\right)$, as well as to $\mathrm{C}=\mathrm{O}$ groups from urea or amides. The spectrum of sample 2 (red line, Figure $5 b$ ) is very similar to the spectra of the other samples obtained under analogous conditions at lower temperatures $[117,135,145]$ but is also similar to HCN-derived polymers synthetized from net $\mathrm{HCN}$ and pure $\mathrm{NH}_{3}$ [146], from liquid $\mathrm{HCN}$ and $\mathrm{NEt}_{3}$ in acetonitrile [147], or from gaseous $\mathrm{HCN}$ and aqueous $\mathrm{NH}_{3}$ [148]. In addition, laboratory 
simulations of Jupiter's and Titan's tholins [149-151] showed IR reflectance spectra that were similar to the spectra of HCN polymers [143,152]. Coll et al. [153] indicated that the IR spectrum of poly-HCN prepared under anhydrous conditions [144] had a similar appearance to Titan's tholins synthesized at low temperatures; thus, poly-HCN could be the base of the tholins. However, McDonald et al. [151] concluded that the resemblances between the IR spectra of Jupiter's tholins and HCN polymers were only the result of similar functional group distributions rather than of a detailed structural identity.
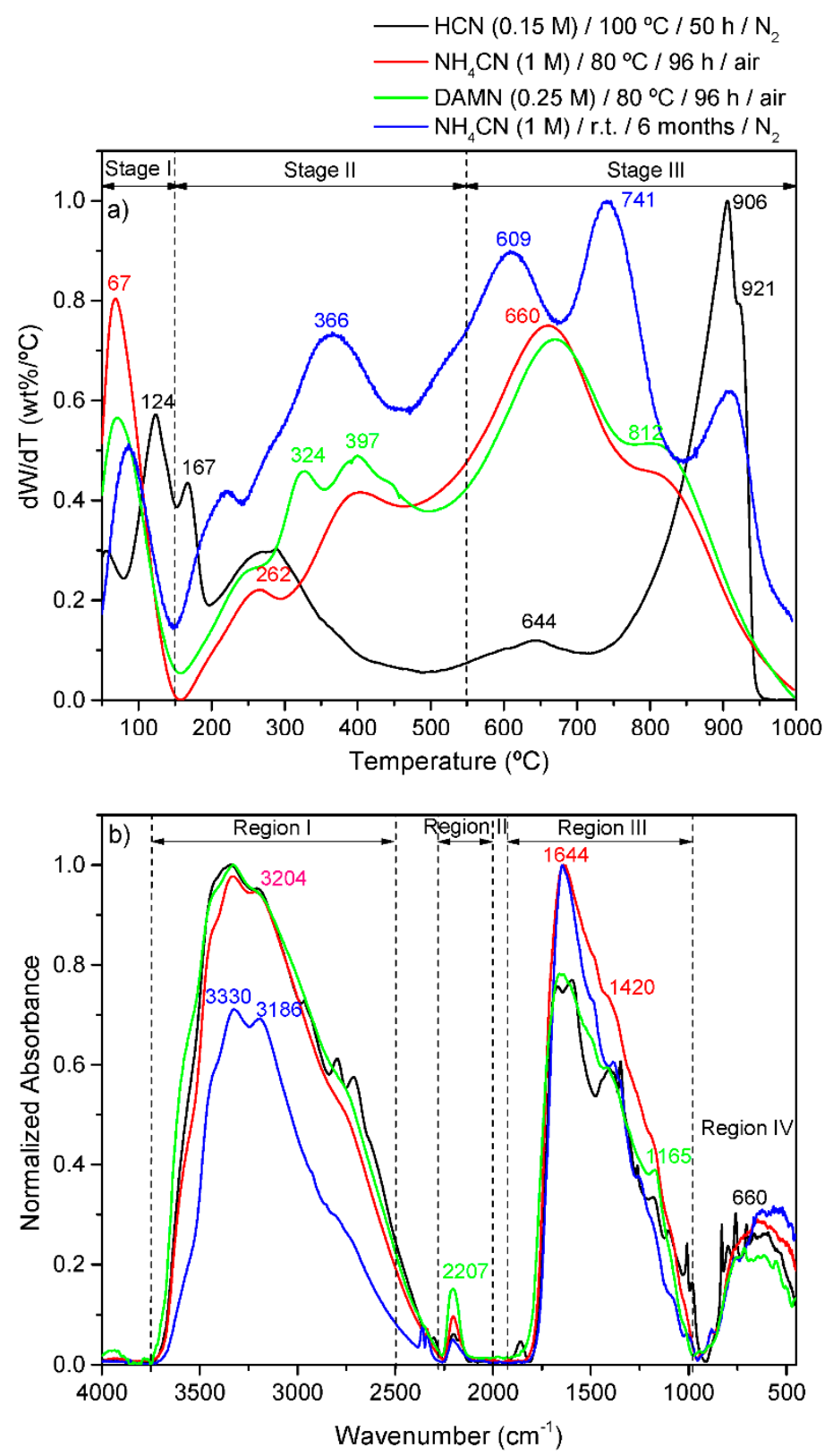

Figure 5. HCN-derived polymers synthesized under different experimental conditions: (a) differential thermogravimetry (DTG) curves; (b) Fourier transform infrared (FT-IR) spectra.

Recently, it has been shown with certainty that the characteristics and properties of tholins are dependent on the simulated planetary conditions used in their production. Moreover, the same effect is observed with HCN-derived polymers, as shown above. Thus, it is not possible to determine a direct relationship between the nature of tholins and that of HCN polymers $[94,102,154,155]$. Finally, the differential scanning calorimetry (DSC)-grams and their corresponding deconvolutions can also provide complementary 
tracks to corresponding DTG curves between samples that will seem highly similar using other analytical and spectroscopic techniques. In general, the deconvolution of the thermal curves offers an ideal signature in comparative studies [140].

\subsection{X-ray Photoelectron Spectroscopy (XPS)}

XPS is a surface spectroscopic technique based on the photoelectric effect that can identify elements that exist within a material or cover its surface, as well as their chemical state and the overall electronic structure and density of the electronic states present in the material. Thus, it is quite a useful tool for the characterization of HCN-derived coatings. The elemental compositions and thicknesses of these coatings as well as the chemical stages of the present elements can be determined by this technique [122,124-127,138]. For example, for AMN-derived coatings, contributions to the $\mathrm{C} 1 \mathrm{~s}$ core level were identified as follows: (i) $\mathrm{C} 1, \mathrm{C}-\mathrm{C}$ and $\mathrm{C}-\mathrm{H}$; (ii) $\mathrm{C} 2, \mathrm{C}-\mathrm{N}, \mathrm{C}=\mathrm{N}, \mathrm{C} \equiv \mathrm{N}$, and $\mathrm{C}-\mathrm{O}$ based groups; (iii) $\mathrm{C} 3,(\mathrm{~N}-) \mathrm{C}=\mathrm{O}, \mathrm{O}-\mathrm{C}-\mathrm{O}$ and N-C-O; (iv) C4, O-C=O based groups; and (v) C5, unsaturated/aromatic carbons with bending energies of 285, 286.7, 288, 289 and $291 \mathrm{eV}$ [122,124]. For these particular coating cases, the thicknesses of the layers ranged from 5 to $10 \mathrm{~nm}$.

In addition, XPS spectroscopy has been used not only to characterize these novel coatings but also to elucidate the chemical structures of black, insoluble HCN-derived polymers. For a $\mathrm{HCONH}_{2}$ polymer, the following components were assigned for the $\mathrm{C} 1 \mathrm{~s}$ region: (i) C1, C-H (284.61 eV); (ii) C2, C-N (286.02 eV); and (iii) C3, C=N (287.9 eV); for the $\mathrm{N} 1 \mathrm{~s}$ region, the following components were determined: (i) $\mathrm{C}=\mathrm{N}(398.4 \mathrm{eV})$; and (ii) $\mathrm{C}-\mathrm{NH}_{2}$ $(399.7 \mathrm{eV})$ [116]. For other $\mathrm{HCONH}_{2}$ polymers, the analysis of the $\mathrm{C} 1 \mathrm{~s}$ signal indicated the following components: $\mathrm{C}-\mathrm{N}, \mathrm{C}=\mathrm{N}, \mathrm{C}-\mathrm{C}$ and $\mathrm{C}-\mathrm{O}$; for the $\mathrm{N} 1 \mathrm{~s}$ signal: $\mathrm{C}-\mathrm{N}$ or $-\mathrm{C} \equiv \mathrm{N}$ and $\mathrm{C}=\mathrm{N}$ were determined [156]. For an $\mathrm{NH}_{4} \mathrm{CN}$ polymer synthesized at $38^{\circ} \mathrm{C}$, the components related to the $\mathrm{N} 1 \mathrm{~s}$ were (i) $-\mathrm{C}=\mathrm{N}$ (imines) $/-\mathrm{N}=\mathrm{C}$-(heterocycles) $(397.4 \mathrm{eV}$ ); (ii) $-\mathrm{CO}-\mathrm{N}$ (amides) (398.7 eV); and (iii) -NH-(amines)/-C $\equiv \mathrm{N}$ (nitriles)/pyrrolyc-NH (400.5 eV). These last components, mainly $-\mathrm{C} \equiv \mathrm{N}$, disappeared after hydrolysis processes in the sample [145].

\subsection{Nuclear Magnetic Resonance (NMR) and Electron Spin Resonance (ESR)}

To the best of our knowledge, only three papers have described the possible structures of HCN-derived polymers by solution-state NMR. The first is a pioneering work by Ferris and co-workers [157] in which the acidic + amphoteric fractions from the ion exchange fractionation of HCN oligomers, synthetized using water solutions of HCN $(0.1 \mathrm{M})$ at $\mathrm{pH}=9.2$ (reached with concentrated $\mathrm{NH}_{4} \mathrm{OH}$ ) and stored in the dark from 4 to 12 months at an ambient temperature [30], were studied by ${ }^{1} \mathrm{H}$ and ${ }^{13} \mathrm{C}$ NMR. The ${ }^{1} \mathrm{H}$ NMR spectrum in DMSO- $d_{6}$ showed three main resonances at $6.80,7.31$ and $7.80 \mathrm{ppm}$, which were related to the N-H bonds, and a minor signal at $2.1 \mathrm{ppm}$, which may have been assigned to aliphatic hydrogens. The ${ }^{13} \mathrm{C}$ NMR spectrum exhibited a main signal at $161.2 \mathrm{ppm}$ consistent with a urea carbonyl group, and other resonances were assigned to the following: $\mathrm{C}=\mathrm{O}$ group from amides, carboxylic acids or ester carbonyl (169.5 ppm); carbonate, carbamate or N-substituted urea carbonyl (156.1 ppm); >C-OH (60.0 ppm); >C-NH- (52.2 ppm); and $-\mathrm{CH}_{3}$ or $-\mathrm{CH}_{2}-(24.7 \mathrm{ppm})$. Note that in this case, a long acquisition time (25,000 scans) was needed to record a ${ }^{13} \mathrm{C}$ NMR spectrum with very weak resonances (related to the intensity of the solvent signal). In this work, no plausible structure for HCN oligomers was proposed, and only the absence of peptide bonds in the structure was established.

The second work described the synthesis of HCN oligomers from HCN gas ( 0.25 mole) and concentrated $\mathrm{NH}_{4} \mathrm{OH}(20 \mathrm{~mL})$ maintained at room temperature for four days. The study of the precipitated solid by ${ }^{1} \mathrm{H}$ NMR was performed using trifluoroacetic acid (TFA) as the solvent, and in the case of ${ }^{13} \mathrm{C} N M R$, an $\mathrm{H}_{3} \mathrm{PO}_{4}-\mathrm{D}_{2} \mathrm{O}$ mixture was employed as the solvent [148]. In the ${ }^{1} \mathrm{H}$ NMR spectrum, only a triplet associated with the $\mathrm{NH}_{4}{ }^{+}$cation and a broad signal (very weak) at 8-9 ppm associated with the $\mathrm{N}-\mathrm{H}$ proton were observed. The ${ }^{13} \mathrm{C}$ NMR spectrum presented a broad resonance at 170-140 ppm, with a main signal at $\sim 160$ ppm, attributed to conjugated $-\mathrm{C}=\mathrm{N}$ - bonds. Although carbonyl carbons associated with urea or similar small molecules cannot be discarded, weak resonances at 115 and 
$\sim 40 \mathrm{ppm}$ were also observed. The resolution of the ${ }^{13} \mathrm{C}$ NMR spectrum of this solution was quite poor even after 50,000 scans. In any case, Umemoto et al., based on these spectroscopic results and other complementary data, proposed a single-ladder structure (all the structures proposed in this section will be commented on and represented in detail in the next sections and will be called ladder structures, Völker's model, Umemoto's model, hetero-polypeptide Matthews' model, and so on).

The third NMR solution study was more recently reported by He and colleagues [115], wherein pure $\mathrm{H}^{13} \mathrm{C}^{15} \mathrm{~N}$ was polymerized in the presence of $\mathrm{NH}_{3}$ gas $(0.5 \%)$ at room temperature for $12 \mathrm{~h}$, and the brown-black solid was collected and directly dissolved in DMSO- $d_{6}$ and analysed by multidimensional ${ }^{1} \mathrm{H},{ }^{13} \mathrm{C}$ and ${ }^{15} \mathrm{~N}$ NMR experiments with different decoupling methods. For example, the ${ }^{1} \mathrm{H}$ NMR spectrum displayed two groups of broad resonances at 9.0-5.5 ppm and at 3.5-1.5 ppm along with some small, sharp peaks in minor percentages, indicating extensive polymerization. The ${ }^{1} \mathrm{H}$ decoupling ${ }^{13} \mathrm{C}$ NMR spectrum presented a strong resonance at $190-140 \mathrm{ppm}$ associated with $\mathrm{C}=\mathrm{N}$ functionality $(162.5,159.6$ and $157.9 \mathrm{ppm}$ from the $\mathrm{C}=\mathrm{N}$ groups and $162.9 \mathrm{ppm}$ from the $\mathrm{H}-\mathrm{C}=\mathrm{N}$ - group), a signal at $135-110 \mathrm{ppm}$ from the carbon in the $\mathrm{C}=\mathrm{C}$ or $\mathrm{C} \equiv \mathrm{N}$ bonds (especially at $113.9 \mathrm{ppm}$ from a nitrile $\mathrm{C} \equiv \mathrm{N}$ ) and finally a signal in the range of $100-60 \mathrm{ppm}$ associated with the carbon in single C-N bonds. As a result of these analyses obtained through all the discussed complementary NMR spectra, poly-imine chain-like structures were proposed. The resolution of these spectra was better than those previously reported in previous works due to the advances of the NMR technique, but were not comparable to other polymeric structures reported with well-defined NMR signals. These results seem to indicate the heterogeneous nature of the structures of $\mathrm{HCN}$-derived polymers, despite their well-known robustness and full reproducible synthesis when the experimental conditions are fixed [117].

On the other hand, solid-state NMR experiments are preferably chosen for the characterization of HCN-derived polymers against solution NMR spectra due to the scarce solubility of the common deuterated solvents of these complex substances. Above, the lack of peptide bonds postulated by Ferris et al. in the subfractions from the soluble HCN oligomers was explained. Below, a series of solid-state NMR spectra studies carried out by Matthews' group will be discussed, as these studies attempted to demonstrate the opposite result, the formation of peptide bonds from the polymerization of HCN [158-160]. To prepare a sample in this first solid-state NMR study, an equimolar mixture of $\mathrm{H}^{13} \mathrm{C}^{15} \mathrm{~N}+\mathrm{H}^{12} \mathrm{C}^{14} \mathrm{~N}$ was polymerized for three days in the presence of $\mathrm{NEt}_{3}$ at room temperature. After that, the sample was put into water for 30 days [159]. The solid-state single- and double-cross polarization ${ }^{15} \mathrm{~N}$ NMR spectra were recorded before and after the water treatment. As an interpretation of these spectra, the hydrolyzed sample showed two resonances at 220 and $30 \mathrm{ppm}$, which were related to nitrile and amine groups, respectively, a further signal at $240-200 \mathrm{ppm}$ assigned to azomethine functions $(\mathrm{C}=\mathrm{N}$ bonds), and a peak at $\sim 95 \mathrm{ppm}$, which may have been related to the presence of peptide bonds. In this work, the authors suggested a non-homogeneous nature for $\mathrm{HCN}$ polymers but with a mixture of N-heterocycle conjugated structures, linear chains and DAMN.

In the second work [160], HCN polymers were prepared from $\mathrm{H}^{13} \mathrm{C}^{14} \mathrm{~N}+\mathrm{H}^{12} \mathrm{C}^{15} \mathrm{~N}$ or from $\mathrm{H}^{13} \mathrm{C}^{15} \mathrm{~N}+\mathrm{H}^{12} \mathrm{C}^{14} \mathrm{~N}$ and treated using the same treatment previously described. This labelling method for carbon and nitrogen atoms allowed the determination of new bonds formed during the polymerization and hydrolysis processes. The data obtained reinforced the results of the previous report, indicating that the peptidic nitrogen components are not an extended fraction of the insoluble hydrolyzed HCN polymers and that the complexity of the spectra is compatible with many other structures. Deeper NMR studies of these samples were further characterized by cross-polarization magic angle spin (CPMAS) and double cross-polarization (DCP)MAS ${ }^{15} \mathrm{~N}$ and ${ }^{13} \mathrm{C}$ NMR techniques as well as dipolar rotational spin-echo ${ }^{15} \mathrm{~N}$ NMR [158]. The ${ }^{13} \mathrm{C}$ NMR spectra exhibited no aliphatic carbon peaks in the 60-40-ppm range, an observed resonance at $75 \mathrm{ppm}$ was attributed to $\mathrm{sp}^{3}$ carbon bonded to ${ }^{15} \mathrm{~N}$ amines, and a peak at $110 \mathrm{ppm}$ was attributed to olefinic carbons of 
DAMN, which disappeared after hydrolysis. The remaining resonances at 200-110 ppm were assigned to nitrile or $>\mathrm{C}=\mathrm{NH}$ groups. The analysis of all spectra, ${ }^{13} \mathrm{C}$ and ${ }^{15} \mathrm{~N} N M R$, indicated the formation of secondary amides, but the lack of aliphatic carbon resonances was not in agreement with a genuine hetero-polypeptide nature of the $\mathrm{HCN}$ polymers, as was postulated by Matthews. Mamajanov and Herzfeld also recorded the CPMAS ${ }^{13} \mathrm{C}$ and ${ }^{15} \mathrm{~N}$ NMR spectra of $\mathrm{HCN}$ polymers derived from a net-labelled $\mathrm{HCN}, \mathrm{H}^{13} \mathrm{C}^{15} \mathrm{~N}$, in the presence of several catalysts, such as $\mathrm{NEt}_{3}$, hydroquinone, benzoquinone, and acetaldehyde ( $0.5 \%$ in weight) [161]. The main groups of resonances were observed at $180-150$ and $100-70 \mathrm{ppm}$ for ${ }^{13} \mathrm{C}$ and $270-180,108,82$ and $61 \mathrm{ppm}$ for ${ }^{15} \mathrm{~N}$, in contrast with the solution state NMR spectra; in these cases, only 2000-4500 scans were enough to properly record the spectra. The ladder structures and hetero-polypeptides suggested for the HCN polymers were ruled out due to the lack, in all the analysed NMR spectra, of the predicted signals. Instead, the presence of linear poly-imine chains, which eventually led to the formation of saturated two-dimensional (2D) networks, are proposed. The production of crystalline DAMN is proven when polymerization is carried out in the presence of a base. However, a later report provided a new perspective regarding the presence of amide bonds in $\mathrm{HCN}$ polymers, in agreement with Ferris but also with Matthews, who found no peptide bonds but did find secondary amides [145]. The CPMAS ${ }^{13} \mathrm{C}$ NMR spectrum of $\mathrm{NH}_{4} \mathrm{CN}$ polymers synthesized from a water solution of $\mathrm{NaCN}$ and $\mathrm{NH}_{4} \mathrm{Cl}$ (equimolar, $10 \mathrm{M})$ at $38^{\circ} \mathrm{C}$ with a reaction time of three days showed the following resonances after a deconvolution process: $168 \mathrm{ppm}$ (amide groups, $-\mathrm{CONH}_{2}$ or $-\mathrm{CONH}$-); $159 \mathrm{ppm}$ (imine and / or groups $-\mathrm{C}=\mathrm{N}-$ ); a group of resonances at 154,149 and $139 \mathrm{ppm}$ related to the $\mathrm{C}$ atoms of N-heterocycles; a group of less intensive peaks at 130 and $110 \mathrm{ppm}$ assigned to alkenes $(>C=C<$ ) and nitriles $(-C \equiv N)$; and finally a group in 100-60 ppm assigned to $C$ atoms bound to heteroatoms, such as amines $(\mathrm{C}-\mathrm{N})$. These resonances were proposed to be compatible with a cyclic polyamide but also with poly-imidazols or macrostructures based on pyrrole and dihydro-pyrazine rings. A more detailed study of the CPMAS ${ }^{13} \mathrm{C}$ NMR of analogous $\mathrm{NH}_{4} \mathrm{CN}$ polymers and DAMN polymers synthesized at $80{ }^{\circ} \mathrm{C}$ using a more exhaustive application of the fitting/band resolution methodology led to the identification of approximately 45 resonances in the range of 190-100 ppm [117]. In this work, the probable formation of a conjugated extended macrostructure formed mainly by several N-heterocycles but also by O-heterocycles, which are, in turn, mainly formed by quaternary carbon atoms in a highly conjugated matrix, was demonstrated, as inferred from CP non-quaternary suppression (NQS) experiments [117]. Figure 6 shows the CPMAS ${ }^{13} \mathrm{C}$ NMR spectra of several HCN polymers as an example in which different synthetic conditions give polymers with different spectroscopic characteristics. In these cases, all the syntheses were carried out using water as the reaction medium.

Finally, the thermal treatment of DAMN or formamide produces $\mathrm{HCN}$-derived polymers, which were also characterized by NMR. Again, Mamajanov and Herzfeld performed several NMR experiments to elucidate the structure of a DAMN polymer synthesized from isothermal heating of recrystallized DAMN at $125^{\circ} \mathrm{C}$ for $12 \mathrm{~h}$ in an argon atmosphere [162]. The obtained CPMAS ${ }^{13} \mathrm{C}$ NMR spectrum presented a unresolved broad band centered at $157 \mathrm{ppm}$, and the CPMAS ${ }^{15} \mathrm{~N}$ NMR spectrum exhibited three broad resonances at $\sim 234 \mathrm{ppm}$ (unsaturated nitrogen), $\sim 146 \mathrm{ppm}$ (pyrrole) and $\sim 83 \mathrm{ppm}$ (ene-amine). These results suggest a poly-amino-imidazole macrostructure. In addition, Cataldo and co-workers obtained $\mathrm{HCN}$-derived polymers from the thermolysis of $\mathrm{HCONH}_{2}$ at $220^{\circ} \mathrm{C}$ for $17 \mathrm{~h}$ or at $185^{\circ} \mathrm{C}$ for $40 \mathrm{~h}$. After an exhaustive workup, a black solid was collected and studied using several techniques, kept similar between the samples using NMR spectroscopy [142]. The CPMAS ${ }^{13} \mathrm{C}$ NMR spectrum presented resonances at 162 and $151 \mathrm{ppm}$ related to azomethine groups, at 142 and $135 \mathrm{ppm}$ assigned to aromatic carbons, at $118 \mathrm{ppm}$ (nitrile groups), at $35 \mathrm{ppm}$ (carbon atoms with amine groups) and at 20 and $10 \mathrm{ppm}$ related to methyl or alkyl groups not previously observed in the $\mathrm{HCN}$-derived polymers described above. In this case, the authors did not propose a structural model for their $\mathrm{HCONH}_{2}$ polymers 
but indicated that "there are clear evidences that it does not exist only one poly(hydrogen cyanide)", as is continuously underlined within these pages.

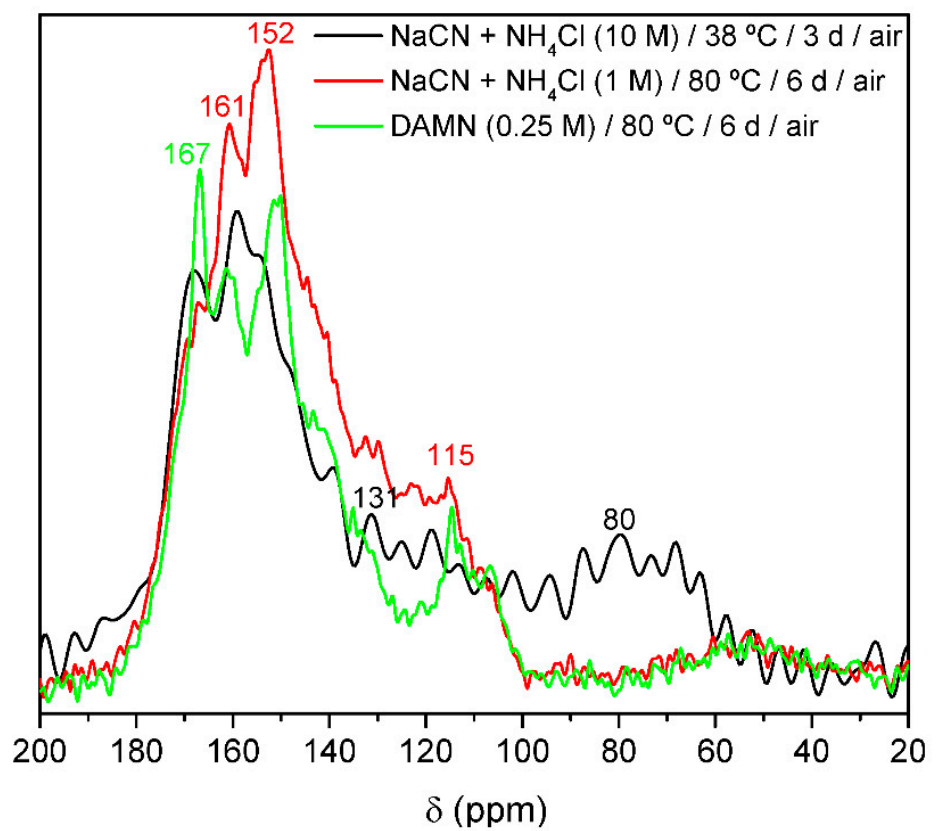

Figure 6. Cross-polarization magic angle spin (CPMAS) ${ }^{13} \mathrm{C}$ Nuclear Magnetic Resonance (NMR) spectra of several HCN-derived polymers synthesized using water as the solvent.

Other resonance studies have included the structural elucidation of $\mathrm{HCN}$-derived polymers using ESR. The use of this technique for the research of an HCN polymer, synthetized from a solution of net $\mathrm{HCN}$ in acetonitrile using a catalytic amount of $\mathrm{NEt}_{3}$ and magnetically stirred at room temperature for two days, indicated that HCN polymer mixtures contain a significant amount of long-lived organic free radicals that are primarily carbon-based and likely supported the generation of radical intermediates during HCN polymerization [101]. In contrast, the ESR data from the $\mathrm{NH}_{4} \mathrm{CN}$ polymers synthesized from water solutions of $\mathrm{KCN}$ and $\mathrm{NH}_{4} \mathrm{Cl}$ (from 1 to $1.5 \mathrm{M}$ ) at $70{ }^{\circ} \mathrm{C}$ for $80 \mathrm{~h}$ provided the following information: These $\mathrm{HCN}$-derived polymers contained paramagnetic sites (free radicals) in a ratio of 1 paramagnetic site $/ 20,000 \mathrm{HCN}$ monomer units, and the locations of these sites in the macrostructure and their real roles in the cyanide polymerization process or in the subsequent reactivity of the final cyanide polymers are unknown [163].

\subsection{X-ray Diffraction (XRD)}

The XRD patterns for some examples of $\mathrm{NH}_{4} \mathrm{CN}$ and DAMN polymers are shown in Figure 7. A peak centered at $\sim 27.2^{\circ}$ was observed in $\mathrm{NH}_{4} \mathrm{CN}$ polymers corresponding to d spacings around 3.2-3.3 $\AA[52,117,118]$. These XRD profiles for the $\mathrm{NH}_{4} \mathrm{CN}$ polymers were very similar to those observed for layered carbonitrides, which showed XRD patterns with a peak at $2 \theta=27.5^{\circ}$, which is related to the (002) diffraction typically found in layered crystal structures. This result seemed to indicate the presence of graphite-like 2D structures in the complex macrostructure of the $\mathrm{NH}_{4} \mathrm{CN}$ polymers. About $40-70 \%$ of the $\mathrm{NH}_{4} \mathrm{CN}$ polymer samples presented crystallinity, and the rest could be considered to be disordered materials. This \% of crystallinity increases with the temperature, and the peak center at $27.2^{\circ}$ is also narrowed in an identical way (Figure 7). These last results might indicate that a higher temperature of polymerization leads to more ordered $\mathrm{NH}_{4} \mathrm{CN}$ polymers and therefore to more thermodynamically stable macrostructures.

In the case of DAMN polymers, similar peaks were observed at $2 \theta=27.28^{\circ}$ with similar interlayer distances [117], which may also be related to graphite-like 2D structures, but also other minor peaks at $25.58^{\circ}\left(002^{\prime}\right.$, Figure 7$)$. In addition, these DAMN samples 
showed two (100) reflections at $2 \theta=15.18^{\circ}(100,3.27 \AA)$, with a higher intensity, and at $2 \theta=11.88^{\circ}\left(100^{\prime}, 3.27 \AA\right)$, as shown in Figure 7 . These multiple peaks for DAMN polymers might indicate a greater diversity of the likely 2D structures present in its structure. Thus, two different blocks could form the DAMN polymer samples. In the case of the DAMN polymers, synthetized at $80^{\circ} \mathrm{C}$, the crystallinity of the samples was about $50 \%$.

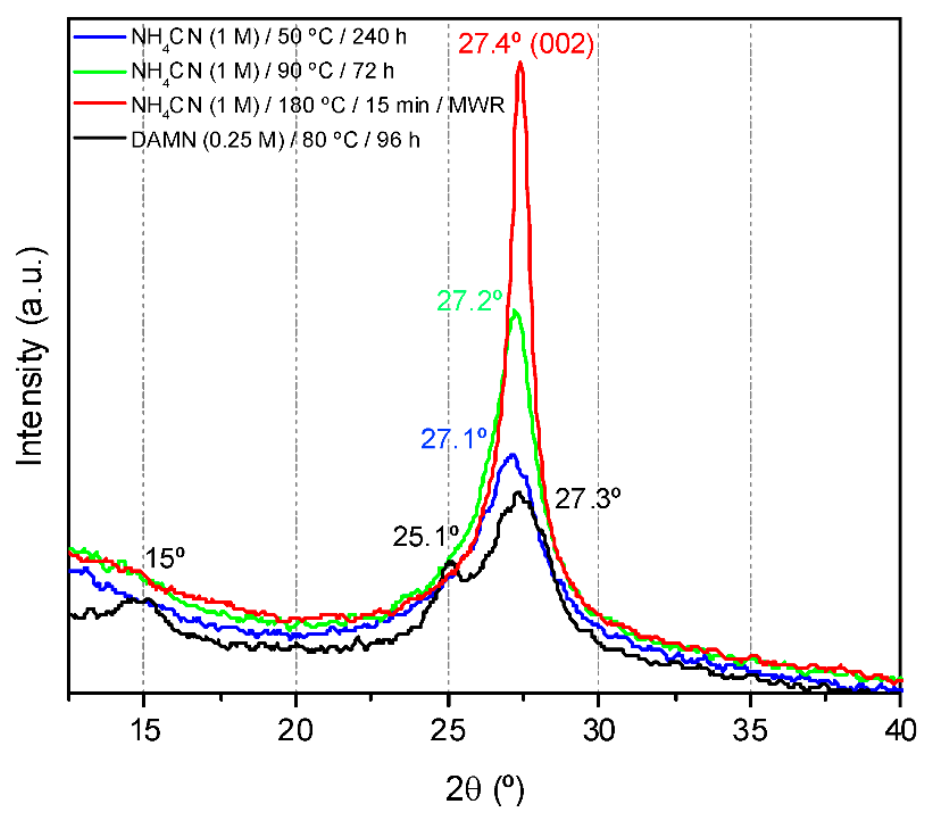

Figure 7. Representative $\mathrm{X}$-ray diffraction patterns of $\mathrm{NH}_{4} \mathrm{CN}$ and DAMN polymers synthesized at different temperatures and at limit conversions for each case. $\mathrm{MWR}=$ microwave radiation. In all cases the $\mathrm{HCN}$-derived polymers were produced in the presence of air.

\subsection{UV-Vis Spectroscopy}

UV-vis spectroscopy has been used to provide both a kinetic approach to the polymerization process of cyanide to understand the pathway of the reaction and a structural characterization of $\mathrm{HCN}$-derived oligomers/polymers. Figure 8 shows some examples of the UV-vis spectra of sol and gel fractions obtained from several cyanide polymerization processes.

The oligomerization of HCN to DAMN was first followed by measuring the absorption of the solutions at $296 \mathrm{~nm}\left(\lambda_{\max }\right.$ of the tetramer), and it was determined that the maximum rate at $25^{\circ} \mathrm{C}$ was reached at $\mathrm{pH}=9.2$ (the $\mathrm{pK}_{\mathrm{a}}$ of the $\mathrm{HCN}$ ) [25]. Using this same protocol, the influence of the synthetic conditions, such as temperature, $\mathrm{pH}$, concentration and $\mathrm{UV}$ radiation, on the DAMN production rate from $\mathrm{HCN}$ was analysed. In the $\mathrm{pH}$ range of 7-10, two processes compete: hydrolysis to form formamide and formic acid (1st order in $\mathrm{HCN}$ ) and polymerization to form new $\mathrm{C}-\mathrm{C}$ bonds (4th order in $\mathrm{HCN}$ ). Both reactions are equivalent, occurring in a range of temperatures from 0 to $60^{\circ} \mathrm{C}$ at $\mathrm{pH}$ values of $8-9$ and considering initial concentrations of $\mathrm{HCN}$ from 0.01 to $0.1 \mathrm{M}$. Additionally, it was determined that freezing at the eutectic point favors concentration and HCN polymerization [26]. Following this methodology, the effect of clays in the oligomerization of HCN was also studied, as commented on above [85].

In more recent works, UV-vis spectra of the final raw solutions have been used to reveal the effects of experimental parameters on the kinetics of cyanide polymerization under aqueous conditions. The joint effect of several factors, such as temperature, salinity and the presence or absence of oxygen and ammonium, was determined using an absorbance ratio, $A_{230} / A_{300}$, against the reaction time and by fitting the curves to a Hill equation. A total of 24 reaction conditions were evaluated over time. The UV-vis spectra of all solutions were monitored over time from 1 to $700 \mathrm{~h}$, showing two bands centered at $\sim 230$ and $\sim 300 \mathrm{~nm}$. 
The first band was related to $\alpha, \beta$-unsaturated nitriles and to amides and lactams, which increased with time, thus pointing out the polymerization progress. The second band disappeared over time, indicating the transformation of cyanide and/or DAMN to other products. The statistical test of the scaling factor $n$ obtained from the fittings to the Hill function showed that the temperature was the main kinetic variable, as expected, and that ammonium and oxygen had significant catalytic effects, with no clear influence of salinity [164].

Table 1. Molar relationships found for representative insoluble HCN-derived polymers synthesized under aqueous conditions (with the exception of entries 31 and 32) and using different experimental temperature, concentration, reaction time and initial $\mathrm{pH}$ parameters. The presence of air $(+)$ is also considered due to its influence on the HCN polymerization processes. r.t. $=$ room temperature; $\mathrm{d}=$ days; $\mathrm{h}=$ hours; $\mathrm{m}=$ months. ${ }^{*}$ polymerization driven by microwave irradiation.

\begin{tabular}{|c|c|c|c|c|c|c|c|c|c|c|}
\hline Entry & Reactants & c (M) & $\mathrm{T}\left({ }^{\circ} \mathrm{C}\right)$ & $\mathbf{t}$ & Air & $\mathrm{C} / \mathrm{H}$ & $\mathrm{C} / \mathrm{N}$ & $\mathrm{C} / \mathrm{O}$ & N/O & Ref. \\
\hline 1 & $\mathrm{NaCN}+\mathrm{NH}_{4} \mathrm{Cl}$ & 1 & 38 & $30 \mathrm{~d}$ & + & 0.77 & 1.07 & 2.51 & 2.36 & {$[139,145$} \\
\hline 2 & $\mathrm{NaCN}+\mathrm{NH}_{4} \mathrm{Cl}$ & 1 & 38 & $30 \mathrm{~d}$ & - & 0.74 & 1.14 & 2.43 & 2.14 & [135] \\
\hline 3 & $\mathrm{NaCN}+\mathrm{NH}_{4} \mathrm{Cl}$ & 1 & r.t. & $30 \mathrm{~d}$ & - & 0.75 & 1.08 & 2.62 & 2.44 & [140] \\
\hline 4 & $\mathrm{NaCN}+\mathrm{NH}_{4} \mathrm{Cl}$ & 1 & 38 & $3 d$ & + & 0.69 & 1.04 & 2.80 & 2.68 & [141] \\
\hline 5 & $\mathrm{NaCN}+\mathrm{NH}_{4} \mathrm{Cl}$ & 1 & 38 & $10 \mathrm{~d}$ & + & 0.69 & 1.02 & 2.83 & 2.78 & [141] \\
\hline 6 & $\mathrm{NaCN}+\mathrm{NH}_{4} \mathrm{Cl}$ & 1 & r.t. & $6 \mathrm{~m}$ & - & 0.74 & 1.09 & 1.39 & 1.27 & {$[140]$} \\
\hline 7 & $\mathrm{NaCN}+\mathrm{NH}_{4} \mathrm{Cl}$ & 1 & 50 & $10 \mathrm{~d}$ & + & 0.82 & 1.13 & 3.54 & 3.14 & [118] \\
\hline 8 & $\mathrm{NaCN}+\mathrm{NH}_{4} \mathrm{Cl}$ & 1 & 60 & $7 \mathrm{~d}$ & + & 0.84 & 1.15 & 3.42 & 2.98 & [118] \\
\hline 9 & $\mathrm{NaCN}+\mathrm{NH}_{4} \mathrm{Cl}$ & 1 & 70 & $5 \mathrm{~d}$ & + & 0.83 & 1.18 & 3.58 & 3.03 & [118] \\
\hline 10 & $\mathrm{NaCN}+\mathrm{NH}_{4} \mathrm{Cl}$ & 1 & 75 & $7 \mathrm{~d}$ & - & 1.29 & 1.21 & 2.66 & 2.19 & [137] \\
\hline 11 & $\mathrm{NaCN}+\mathrm{NH}_{4} \mathrm{Cl}$ & 1 & 90 & $2 \mathrm{~d}$ & + & 0.84 & 1.17 & 2.94 & 2.5 & [118] \\
\hline 12 & $\mathrm{NaCN}+\mathrm{NH}_{4} \mathrm{Cl}$ & 1 & 90 & $2 \mathrm{~d}$ & - & 1.19 & 1.20 & 3.89 & 3.24 & [137] \\
\hline 13 & $\mathrm{NaCN}+\mathrm{NH}_{4} \mathrm{Cl}$ & 0.5 & 80 & $4 \mathrm{~d}$ & + & 1.17 & 1.21 & 3.28 & 2.72 & [117] \\
\hline 14 & $\mathrm{NaCN}+\mathrm{NH}_{4} \mathrm{Cl}$ & 1 & 80 & $4 \mathrm{~d}$ & + & 1.39 & 1.20 & 3.91 & 3.25 & [117] \\
\hline 15 & $\mathrm{NaCN}+\mathrm{NH}_{4} \mathrm{Cl}$ & 1 & 80 & $7 \mathrm{~d}$ & + & 1.23 & 1.20 & 6.18 & 5.14 & [117] \\
\hline 16 & Diamino-maleo-nitirile (DAMN) & 0.5 & 80 & $4 \mathrm{~d}$ & + & 1.28 & 1.22 & 4.42 & 3.62 & {$[117]$} \\
\hline 17 & DAMN & 1 & 80 & $4 \mathrm{~d}$ & + & 1.29 & 1.18 & 4.37 & 3.71 & [117] \\
\hline 18 & DAMN & 1 & 80 & $7 \mathrm{~d}$ & + & 1.31 & 1.18 & 2.56 & 2.17 & {$[117]$} \\
\hline 19 & $\mathrm{NaCN}(\mathrm{pH}=9.2)$ & 1 & 38 & $30 \mathrm{~d}$ & + & 0.77 & 1.16 & 2.00 & 1.72 & [135] \\
\hline 20 & $\mathrm{NaCN}(\mathrm{pH}=9.2)$ & 1 & 38 & $30 \mathrm{~d}$ & - & 0.77 & 1.19 & 1.96 & 1.64 & [135] \\
\hline 21 & $\mathrm{NaCN}(\mathrm{pH}=9.2)$ & 1 & r.t. & $30 \mathrm{~d}$ & - & 1.74 & 1.64 & 1.74 & 1.64 & [140] \\
\hline 22 & $\mathrm{HCN}_{(\mathrm{g})}+\mathrm{H}_{2} \mathrm{O}_{(\mathrm{l})}$ & NR & $>60$ & NR & + & 0.64 & 0.77 & 2.37 & 3.07 & [139] \\
\hline 23 & $\mathrm{HCN}_{(\mathrm{l})}+\mathrm{NH}_{3(\mathrm{aq})}$ & NR & 0 & $4 \mathrm{~d}$ & - & 0.70 & 1.14 & 1.84 & 1.62 & [139] \\
\hline 24 & $\mathrm{HCN}_{(\mathrm{g})}+\mathrm{NH}_{3(\mathrm{aq})}$ & 12.5 & r.t. & $4 \mathrm{~d}$ & - & 0.83 & 1.00 & 5.08 & 5.07 & [148] \\
\hline 25 & $\mathrm{HCN}_{(\mathrm{l})}+\mathrm{NH}_{3(\mathrm{aq})}+\mathrm{NEt}_{3}$ & NR & r.t. & $3 d$ & - & NR & 1.07 & 3.89 & 3.62 & [158] \\
\hline 26 & $\mathrm{HCN}_{(\mathrm{aq})}+\mathrm{NH}_{4} \mathrm{OH}$ & 1 & 90 & $16 \mathrm{~h}$ & - & 0.82 & 1.11 & 3.15 & 2.84 & [61] \\
\hline 27 & $\mathrm{HCN}_{(\mathrm{aq})}+\mathrm{NH}_{3(\mathrm{aq})}$ & NR & $40-50$ & $5 \mathrm{~h}$ & - & 0.88 & 1.12 & 3.77 & 3.36 & [144] \\
\hline 28 & $\mathrm{KCN}+\mathrm{NH}_{4} \mathrm{Cl}$ & $1-1.5$ & 70 & $80 \mathrm{~h}$ & + & 0.72 & 1.09 & 3.10 & 2.85 & [163] \\
\hline 29 & $\mathrm{HCN}(\mathrm{pH}<10)$ & 0.15 & 100 & $50 \mathrm{~h}$ & - & 0.62 & 1.36 & 0.57 & 0.42 & [74] \\
\hline 30 & $\mathrm{KCN}+\mathrm{NH}_{4} \mathrm{Cl}$ & 1 & $180 *$ & $0.25 \mathrm{~h}$ & - & 1.13 & 1.3 & 4.14 & 3.2 & [52] \\
\hline 31 & $\mathrm{HCN}_{(\mathrm{l})}+\mathrm{NH}_{3}$ & NR & r.t. & $30 \mathrm{~d}$ & - & 0.93 & 0.99 & - & - & [47] \\
\hline 32 & $\mathrm{HCN}_{(\mathrm{l})}+\mathrm{NH}_{3(\mathrm{~g})}$ & $10: 1$ & r.t. & $51 \mathrm{~d}$ & - & 0.84 & 0.96 & - & - & {$[94,136]$} \\
\hline
\end{tabular}



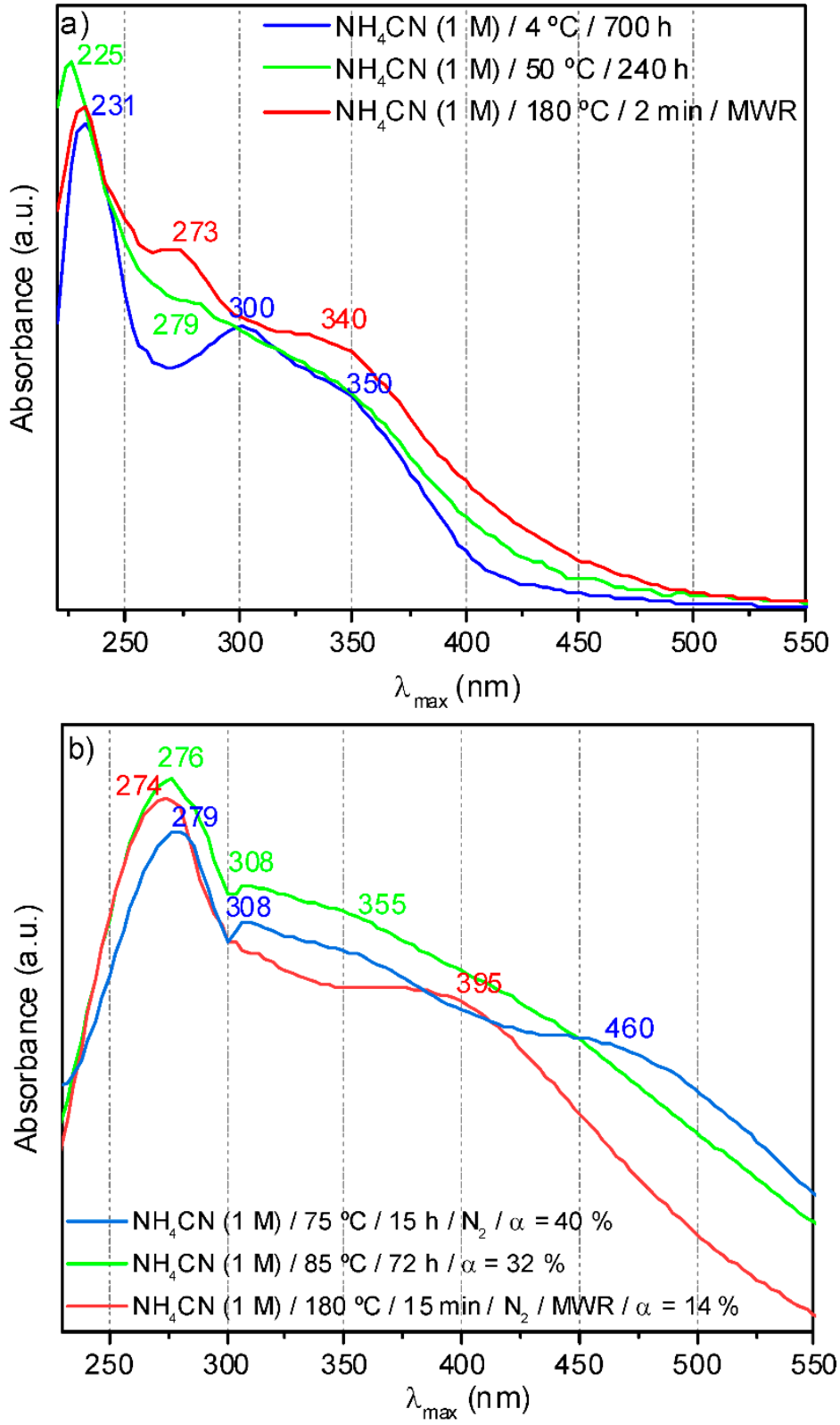

Figure 8. UV-vis spectra: (a) Sol fractions; (b) gel fractions obtained under different synthetic conditions. $\mathrm{MWR}=$ microwave radiation. $\mathrm{N}_{2}$ = reaction carried out under inert atmosphere of nitrogen. Air was present in the rest of reactions.

Ferris and Edelson also determined the important role of oxygen in the kinetics and mechanistic pathways of cyanide polymerization [165]. Although this kinetic approach using UV-vis spectroscopy was valid for the range of temperatures used in this concrete study, $4-38{ }^{\circ} \mathrm{C}$, the model fails at higher temperatures. The values of the scaling factor $n$ found for the reactions conducted at 50 and $60{ }^{\circ} \mathrm{C}$ were not fully in agreement with those calculated when the polymerization was carried out at $38{ }^{\circ} \mathrm{C}$, and a quite deficient fitting to the Hill equation was observed for higher temperatures ranging from 70 to $90{ }^{\circ} \mathrm{C}$ [118]. The UV-vis spectra obtained in the range of $70-90{ }^{\circ} \mathrm{C}$ are clearly more complex than those recorded at lower temperatures, although bands can be observed at $\sim 230$ and $\sim 300 \mathrm{~nm}$. However, in the solutions obtained from the cyanide polymerization according to a simulated hydrothermal environment, using a temperature of $180^{\circ} \mathrm{C}$ under microwave radiation, no bands were identified at $\sim 230$ or $\sim 300 \mathrm{~nm}$, but new bands appeared at 225 , $\sim 260$ and $\sim 340 \mathrm{~nm}$. The variation in this last case of the $A_{260} / A_{340}$ ratio against the reaction 
time did not exhibit a sigmoidal profile; however, a fluctuating behaviour was observed [52]. Therefore, the kinetics of the cyanide polymerization process are markedly dependent on the temperature, as will be additionally discussed below using gravimetric methods.

On the other hand, the kinetics of the deposition of AMN-based coatings were studied by UV-vis spectroscopy. Quartz slides were coated using several AMN solutions at different concentrations. The absorbance at $\lambda=423 \mathrm{~nm}$ was monitored over time, indicating that film growth in the steady state is not compatible with first-order kinetics with respect to the monomer, requiring a heterogeneous nucleation phase to initiate the deposition step. An increase in the reaction rate due to the liquid-air interface was suggested for this coating process [138].

For characterization purposes, freeze-dried oligomeric fractions from $\mathrm{HCN}$ polymerization were measured by Ferris and co-workers using alkaline solutions, and a very strong absorption was observed in the 300-325 nm range [157]. Umemoto et al. also registered the UV-vis spectra of HCN oligomers in TFA solutions before and after hydrogenation processes to confirm the existence of unsaturated $-\mathrm{C}=\mathrm{N}$ - double bonds in the structures of these oligomers [148]. This spectroscopic technique has been additionally used for the characterization of a cyanogen $\left(\mathrm{C}_{2} \mathrm{~N}_{2}\right)$ photopolymer in a THF solution, showing welldefined absorbance bands centered at 228, 305 and $411 \mathrm{~nm}$, related to aromatic heterocyclic compounds [166]. The UV-vis spectrum of an insoluble $\mathrm{NH}_{4} \mathrm{CN}$ polymer in a DMSO solution presents two weak absorption bands at 345 and $465 \mathrm{~nm}$, which can be assigned to an $\mathrm{N}$-heterocyclic macromolecular structure with $\pi$-extended conjugation [145].

\subsection{Kinetic Analyses Based on Gravimetric Methods: Aqueous Polymerizations}

The kinetic approaches using UV-vis spectroscopy showed a direct dependence between temperature and the rate of cyanide polymerization, as mentioned above. To obtain a better understanding of these preliminary results, some studies have been carried out using gravimetric measurements. Thus, the kinetics of the precipitation polymerization of $\mathrm{NH}_{4} \mathrm{CN}$ in water were studied under isothermal conditions at different temperatures ranging from $50{ }^{\circ} \mathrm{C}$ to $90^{\circ} \mathrm{C}$ by means of this methodology $[118,137]$. The use of the Kamal-Sourour autocatalytic kinetic model was proposed to properly describe the overall formation process of these polymers at highest temperatures of $80-90^{\circ} \mathrm{C}$. However, experiments conducted at the lowest polymerization temperatures, from $50-60{ }^{\circ} \mathrm{C}$ demonstrated that this reaction follows $n$ th-order kinetics rather than an autocatalytic mechanism. All of the kinetic parameters determined in these studies, including reaction orders and activation energies, suggested that the polymerization kinetics of HCN cannot be based on a simplistic single mechanism. In addition, the parallel analysis of the data obtained from the structural characterizations of the polymers at different conversion degrees by elemental analysis and FT-IR spectroscopy indicated that the experimental conditions, in this particular case the reaction temperature, have a remarkable effect on the composition and molecular structure of this polymeric system and that different side reactions must occur during the course of the hetero-phase polymerization. Presumably, the selected temperature can alter the polymerization pathways. Some mechanistic aspects will be discussed in the final section of this manuscript to show the plausible complex structures of HCN polymers due to the potential processes implicated in their production.

\subsection{Kinetic Analyses Based on DSC Methods: Bulk Polymerizations}

Although $\mathrm{HCN}$-derived polymers are generally produced using aqueous media, it is also possible to synthetize them in the absence of a solvent. Thus, very recently, a kinetic study of the bulk polymerization of DAMN was reported [167]. In this study, two series of non-isothermal experiments were carried out by differential scanning calorimetry (DSC), and the results indicated that polymerization is initiated at temperatures lower than $\sim 180^{\circ} \mathrm{C}$ (melting point of DAMN) for slow heating rates, while higher heating scans lead to the polymerizations occurring entirely in the liquid phase. From these DSC data obtained under dynamic thermal conditions, a kinetics approach to the melt polymerization of 
DAMN was described that is consistent with an apparent self-acceleration model, $\mathrm{d} \alpha / \mathrm{d} t=k$ $\alpha^{m}(1-\alpha)^{n}$, with a total reaction order $m+n \sim 3$. Note that for this autocatalytic bulk polymerization, the global reaction order is significantly different from that found for the polymerization of cyanide in water, $m+n \sim 20$ [137]. These differences may be related to the role of water during the polymerization processes, which results in more complex pathways. For the melt polymerization of DAMN, TG-DSC-MS analysis under an inert atmosphere demonstrated that the weight loss observed during the polymerization may be mainly related to the deamination and dehydro-cyanation processes. Both reactions occurred simultaneously in practically the same temperature range.

\section{Structural and Mechanistic Considerations and Approaches}

\subsection{Ab Initio Studies to Explain the HCN Oligomerization}

The complex chemistry of HCN has also been addressed by computational studies, again showing a broad chemical space. For example, the exploration of the reaction mechanism for HCN tetramerization by the Tabu-based automated reaction search method led to the generation of 678 tetrameric structures generated from HCN [168]. In this sense, the chemical spaces of HCN polymerization and hydrolysis were studied by combinatorial descriptions using graph grammars [169]. The presence of water was taken into consideration in further computational studies regarding the oligomerization of $\mathrm{HCN}$ to the generation of dimers [170] and trimers [171] and, in addition, regarding the concentrations of HCN molecules in aqueous surfaces [89]. Furthermore, the dimerization of HCN has been computationally explored in interstellar icy grain mantles [172], and the theoretical mechanisms for the production of adenine, a formal pentamer of $\mathrm{HCN}$, have been examined under several prebiotic simulated conditions using quantum chemical calculations [42,173-178]. A pioneering study using MINDO/3 molecular orbital theory showed that HCN oligomerization is an exothermic process, and the first step of oligomerization, the generation of the dimer $\left(\mathrm{H}_{2} \mathrm{C}_{2} \mathrm{~N}_{2}\right)$, is the rate-determining step [179]. Other early papers focused on the stability of $(\mathrm{HCN})_{n}$ oligomers $(n=2,3,4)$ depending on their geometries $[180,181]$.

\subsection{Structural Models Based on Spectrometric and Spectroscopic Measures}

Several models have been described to explain the complex structures of HCN polymers, as shown in Scheme 2 [47,115,144,148,157,161,162,165]. Various polymerization mechanisms have been proposed in the literature since the early 1960s and are, in many cases, more speculative rather than founded on experimental data obtained from diverse characterization techniques. Different types of HCN monomers, such as the dimer iminoacetonitrile, AMN, and DAMN, which has two isomers, cis and trans, have been postulated to explain the polymerization of this weak acid. In principle, all of these monomers may be involved during HCN-polymer formation, and therefore distinct polymeric systems can be simultaneously obtained. This complex and heterogeneous nature of HCN polymers means that their structures have still not been fully characterized. In addition, as mentioned above, the properties of HCN polymers are modified by the synthetic conditions. Therefore, an only structural model must not be considered for all HCN-derived polymers since their structural nature is directly dependent on the reaction settings. These considerations have only been considered since very few years ago.

The molecule $t$-DAMN or diamino-fumaronitrile is suggested to form a ladder structure, Völker's model [144], the earliest model proposed; through a similar mechanism, $c$-DAMN is thought to yield another macrostructure, Umemoto's model [148]. In both cases, polymerization via a $\mathrm{C}=\mathrm{C}$ must be considered initially, yielding a poly-amino-cyanomethylene, and subsequently, different intramolecular cyclization reactions take place. However, the polymerizability of DAMN through the double bond is quite questionable, as was commented on afterwards. Years later, Mamajanov and Herzfeld proposed that these layered covalent polymeric systems are formed by the further addition of one-dimensional (1-D) chains, which are first built up by the head-to-tail addition of HCN monomers [161]. However, the same authors studying the solid-state polymerization of DAMN proposed the 
formation of a poly-aminoimidazole [162]. The formal tetramer of $\mathrm{HCN}$ was also thought to be the key monomer in the polymerization of $\mathrm{HCN}$ by Ferris and co-workers, according to their pioneering studies $[157,165]$. On the other hand, the polymerization of AMN gives poly-amino-malononitrile, which, after reacting with $\mathrm{HCN}$, yields poly-amidine. These poly-amidines can be transformed by hydrolysis to polypeptides according to the studies of Matthews et al. [47]. From this same monomer, or its tautomer, 2-iminoacetimidoyl cyanide, He et al. suggested that the dominating polymeric product is a poly-imine chainlike structure, such as that shown in Scheme 2 [115]. This recent assignment of HCN polymers is based on structural investigations of $\mathrm{HCN}$ polymer isotopomers by means of solution-state multidimensional NMR techniques, as discussed above. In this case, $\mathrm{HCN}$ polymers were prepared from pure $\mathrm{H}^{13} \mathrm{C}^{15} \mathrm{~N}$ by amine catalysis in a polymerization gas phase and under essentially anhydrous conditions. This linear macrostructure is different from the extended triazine structure, which present as 2D sheets and was first suggested by Minard et al. [129].

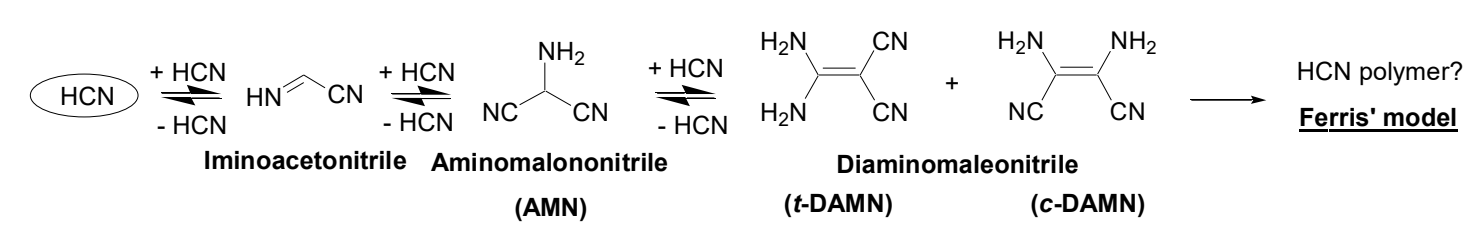

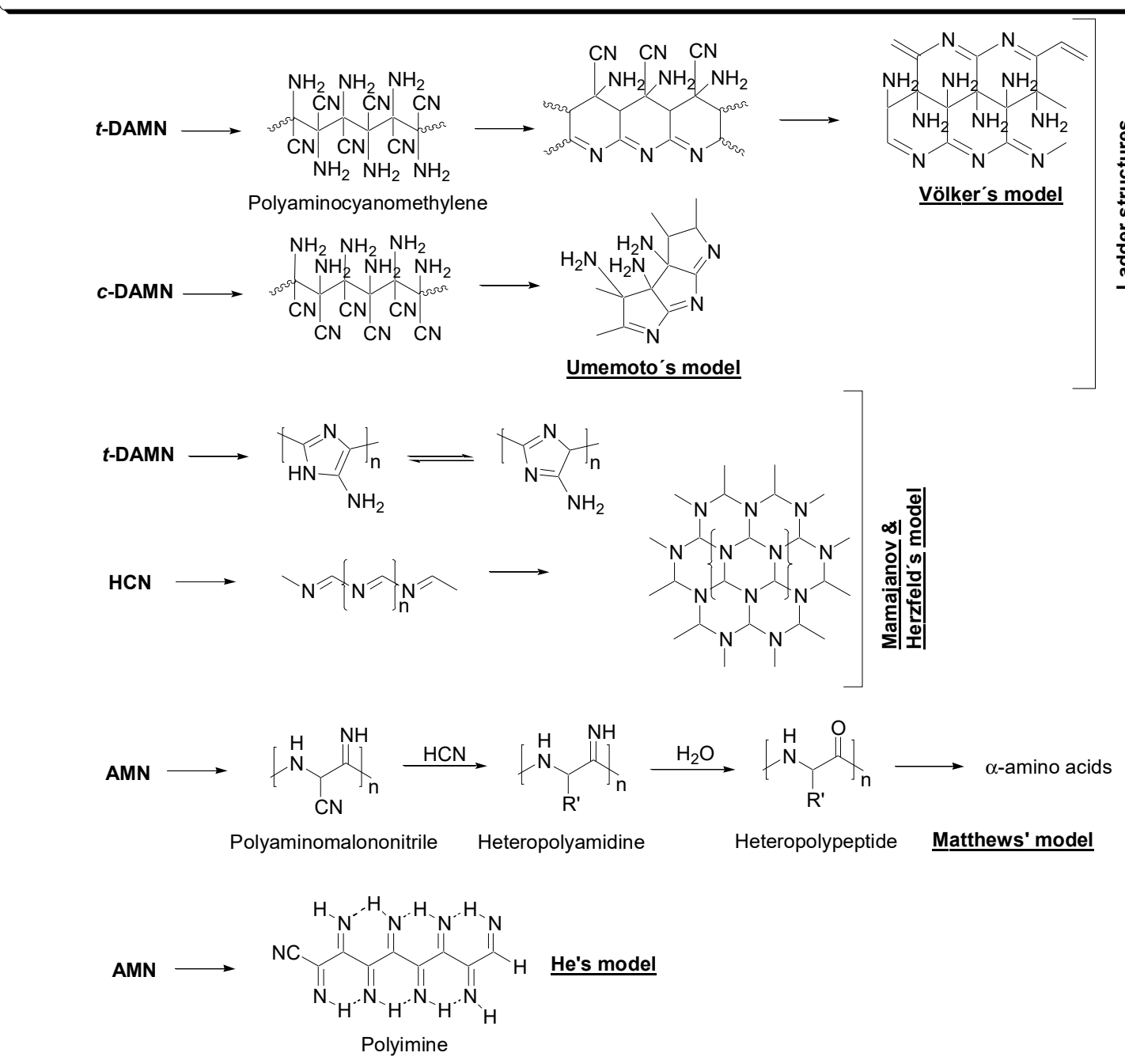

Scheme 2. Traditional proposed models for explaining the structures of HCN-derived polymers. 
Faced with this singular scenario, it is convenient to survey the polymerizability of the different oligomers of HCN. Therefore, the polymerization of imino-acetonitrile is illustrated in Scheme 3. This compound can be polymerized through the imine bond, giving rise to a polyamine with a $>\mathrm{CH}-\mathrm{NH}$ - backbone and with nitriles as pendant groups on the main chain. The chemistry of the polymerization of the $\mathrm{C}=\mathrm{N}$ functional group is relatively unstudied, and thus, these mechanisms are not well understood. Imines that are unsubstituted at the carbon site are usually unstable and cannot be isolated, whereas other imines are very stable and do not polymerize [182]. However, electrophilic imines with one substituent on carbon and electro-withdrawing groups, such as cyano, which is the strongest electrophilic polar group, are active in (co)polymerization. Therefore, the ability of imines to undergo polymerization appears to be very sensitive to the number and nature of the substituents. In this regard, imines are very similar to carbonyl compounds, whose polymerization behaviour is also extremely sensitive to their substitution pattern. The structure of this poly-aminonitrile resembles that of the well-known polyacrylonitrile (PAN). Therefore, the chemistry of PAN can be used as a reference when analyzing the currently studied system. For example, this polymeric system can undergo cyclization and cross-linking reactions in which neighboring nitrile groups react to form six-membered rings, in the same manner as that which occurs in PAN (Pathway a, Scheme 3). However, it should be mentioned that these reactions occur very quickly for PAN, with complete conversion in less than $15 \mathrm{~min}$ when this polymer is in a solution or is melted and the temperature is above $150^{\circ} \mathrm{C}$. At the highest temperatures under thermal treatment, a fully conjugated (aromatic) ladder structure is formed by PAN [183]. Therefore, these data, although useful as a reference, must be used with caution since the formation of cyclic conjugation leads to a dihydropyridine-type structure in the case of PAN, which is different from that of the dihydro-pyrazine obtained in this case. The low probability of this route for poly-aminonitrile is easily recognized, considering the fact that polymerization reactions of $\mathrm{HCN}$ are mainly carried out in solution and at relatively low polymerization temperatures, representing unfavorable experimental conditions for these thermal cyclizations.

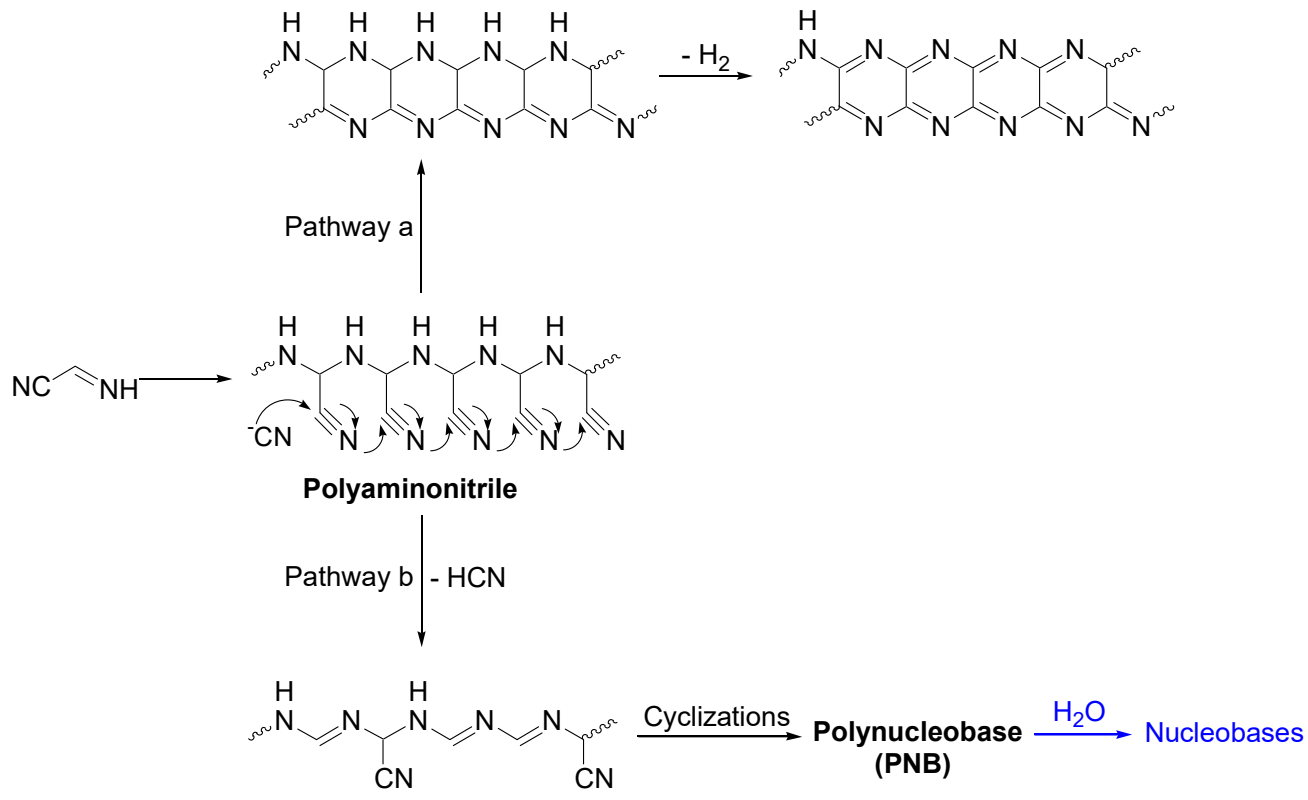

Scheme 3. Generation of HCN-derived polymers from the dimer imino-acetonitrile. 
A different pathway for acquiring the polymer obtained from imino-acetonitrile is also indicated in Scheme 3, Pathway b. Dehydro-cyanation reactions can also take place, giving rise to a poly-imine with the formation of an extended conjugation in the backbone structure. This poly-imine with residual nitrile groups along the main chain, a $\pi$-conjugated segment, has been proposed by Matthews and Minard [92,129]. These authors did not provide any polymerization mechanism for its formation, although they postulated that this polymeric system may undergo thermal and/or photochemical cyclizations to form triazines, purines and pyrimidines linked together in a poly-nucleobase (PNB) macromolecule (see Figure 1 in [92]). Moreover, this PNB can be hydrolyzed into nucleobases. Thus, this model helps to explain the sequence of carbon and nitrogen in purines and pyrimidines.

In Scheme 4, the pathways and structures proposed for the HCN polymers from the trimer AMN are shown, and a general picture of the polymerization reaction in an aqueous medium is presented. Here, it is possible to distinguish two polymerization routes. The first route is based on the initial formation of a linear poly-imine (formulated in Scheme 4 as an oligomer product with twelve monomeric units, 12-mer), postulated by He et al. and indicated in Scheme 2 [115]. Its formation is explained through a decomposition step of AMN to provide a carbene with the elimination of hydrogen cyanide, according to the works of de Vries about the stability of amino-malononitriles in solution [184,185]. It is necessary to involve such intermediate species to understand the oligomerization of AMN, during which its active methine group plays a vital and attacking role, which seems to be a key step in HCN polymerizations in basic aqueous media. However, it is relevant to note that amino-cyano-carbenes are also detected during the thermolysis of aminomalononitriles in refluxing toluene, in the absence of a basic medium [185]. From this linear poly-imine, in the presence of $\mathrm{HCN}$, it is possible to generate a number of realistic and rational structures that can evolve for distinct side reactions according to the dynamic imine chemistry, and most of these structures are constituted by different heterocycles [117]. On the one hand, the nucleophilic attack of the cyanide ion onto the electrophilic carbon atoms of imine units can induce intramolecular cyclization reactions, with the subsequent formation of either stable five- or six-membered rings with a large number of amine groups, after an aromatization process. In Route 1 shown in the upper right part of this scheme, the formation of the final product of fused amino-pyrrole and aminopyridine ladder macrostructures is proposed, and more mechanistic details about their formation were discussed in a recent work by our group [117]. The establishment of a chain incorporating amine pyridine rings is supported in the study of He et al., where they described tetraamino-ciano-pyridine as a side product accompanying poly-imine [115]. Additionally, it is relevant to note the conclusion achieved in the study of Bonnet et al. regarding the compositional and structural investigation of HCN polymers achieved through highresolution mass spectrometry [136]. These authors demonstrated the probable presence of aromatic rings and amine groups in HCN polymers, confirming the N-heterocyclic structures proposed in Scheme 4. The possibility of the partial hydrolysis of the polyimine in aqueous solution leading to a linear poly(imine-ketone) is another possible side reaction, as is described well in the literature [186]. This new partially hydrolyzed and/or oxygenated oligomeric product, over three carbon atoms taken as an example, can evolve in a similar way to that indicated above, giving rise to new heterocyclic macrostructures, as shown in the blue color in the right part of the route shown in the scheme. In this case, the diamino furan and the corresponding $4 \mathrm{H}$-pyran derivatives were formulated from the addition reaction of HCN to a carbonyl carbon instead of to an imine group, and following a cyclization reaction, heterocyclic macrostructures with fused rings of five and six members were exposed. 


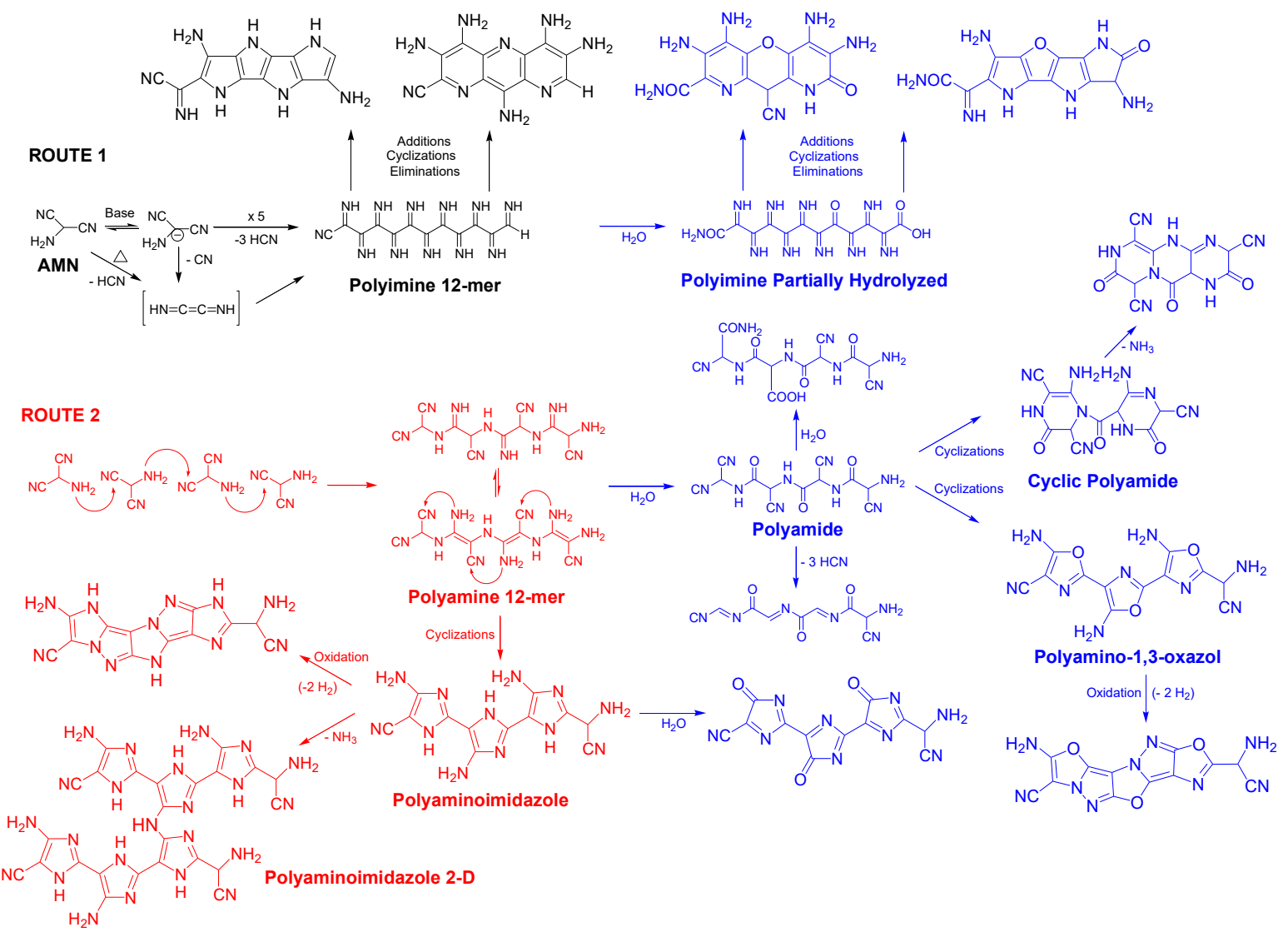

Scheme 4. Hypothetical pathways for the formation of HCN polymers from amino-nalano-nitrile (AMN) with linear growth according to recent works in the literature $[115,117,138]$.

On the other hand, Thissen et al. proposed a new mechanism for AMN polymerization from aqueous solutions, obtaining polymeric films, as indicated in this scheme as Route 2 [138]. This step-growth polymerization is based on the electrophilicity of the carbon center of the nitrile group, which makes it susceptible to a variety of nucleophilic addition reactions. They suggested the formation of a linear polyamine 12-mer by a polyaddition between the amine and cyano groups that evolved to a poly-aminoimidazole by means of intramolecular cyclizations (intramolecular addition) between these same neighboring functional groups. In this case, this polymerization is based on the triple bond $\mathrm{C} \equiv \mathrm{N}$, although these polymerization reactions are rarely reported. The cyano group has been polymerized by cationic, anionic, radical and coordination catalysts; however, the polymerizability of multi-nitrile compounds has scarcely been addressed in the literature [187-189]. Perhaps the most interesting example of nitrile polymerization is that occurring when PAN is heated, as commented on above. Minard et al. detected imidazole ring fragments using a thermal degradation process of $\mathrm{HCN}$ polymers with tetramethylammonium hydroxide at $250{ }^{\circ} \mathrm{C}$ and analysed the volatile products by gas chromatography-mass spectrometry [129]. These findings agree with the proposed macrostructure based on the heterocyclic ring. A poly-amino-imidazole is also in agreement with the finding of Mamajanov and Herzfeld, who studied the polymer sample obtained from the solid-state reaction of crystalline DAMN (see Schemes 2 and 5), which will be evaluated later. Thissen et al. also proposed its hydrolysis to obtain a new macrostructure with carbonyl groups in the imidazole rings, according to experimental compositional data [138]. 


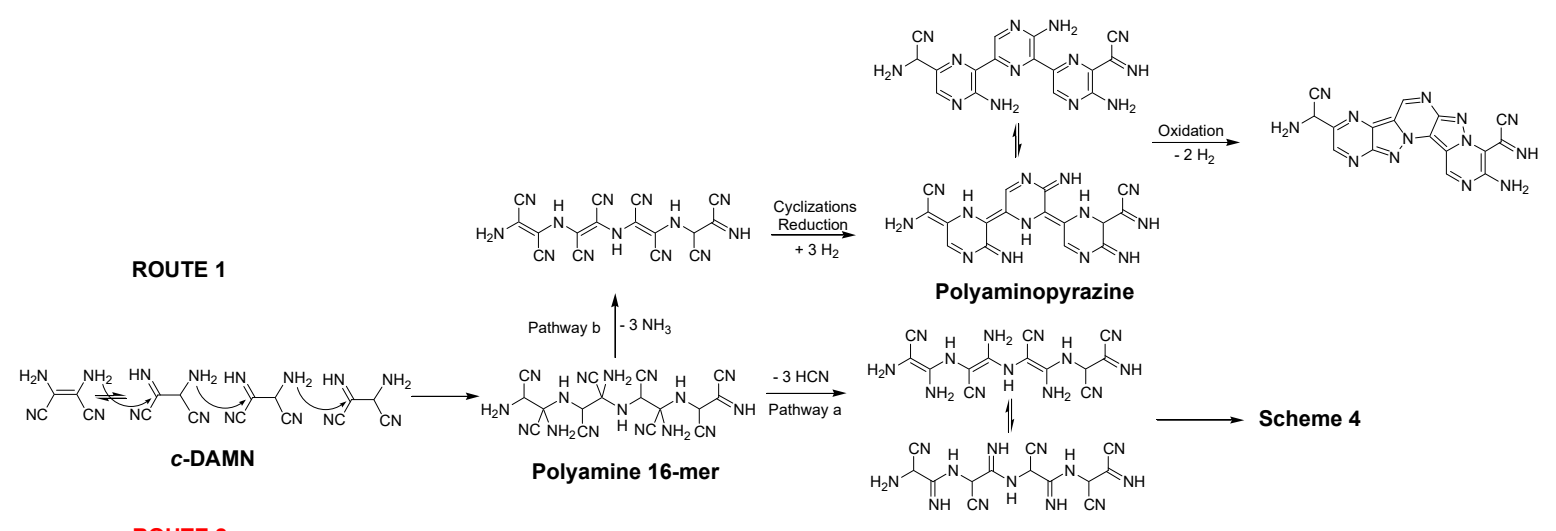

ROUTE 2
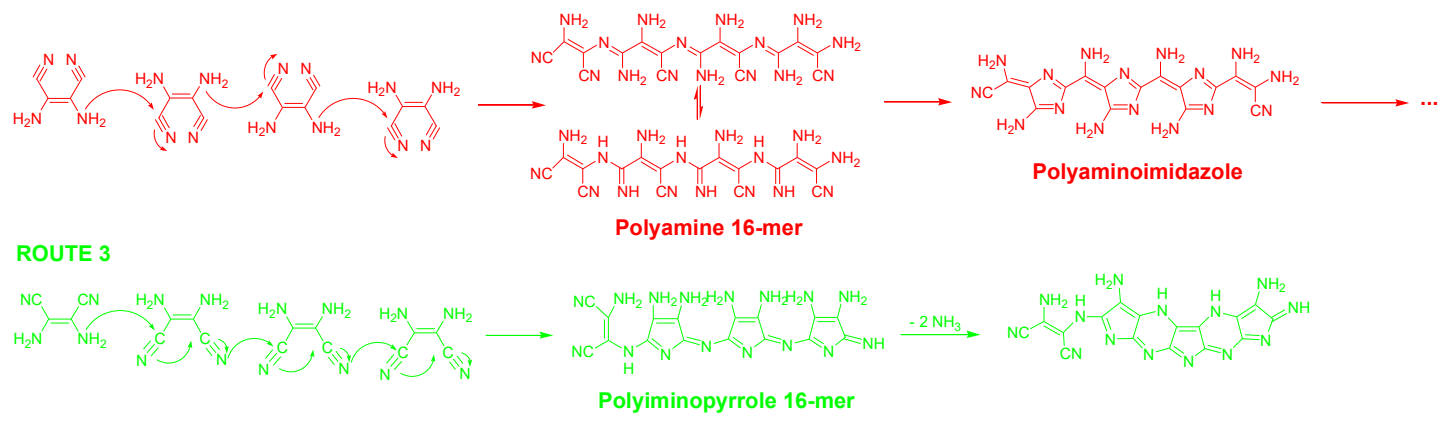

Scheme 5. Hypothetical pathways for the formation of HCN polymers from DAMN according to recent works in the literature.

In Scheme 4, the formulated polyamine is similar to poly-amino-malononitrile, a protopeptide according to Matthews' nomenclature [47]. The formation of this proto-peptide has been proposed by Matthews et al. and is in agreement with the fact that different $\alpha$-amino acids have been observed from the hydrolysis of a hetero-polypeptide (poly-amidine) (see Scheme 2). Logically, in the hydrolysis reaction, a post-polymerization modification, of polyamine must be considered, as well as other hypothetical macrostructures, such as those presented in this scheme. Matthews et al. also proposed this hydrolysis reaction, although these authors did not indicate the high potential of the polyamide to yield repeat cyclic structures. Thus, this linear polyamide can also undergo different intramolecular reactions, yielding new polymeric systems with high degrees of cyclization, as shown in this scheme. It is easy to see that both the proto-peptide and the corresponding polyamide display high cyclization tendencies. This is especially true when you consider the fact that the polymerization reactions were carried out in solution under conditions that are favourable for intramolecular cyclization, affording polymeric systems that have cyclic repeat units of five- and six-membered nitrogenated rings. This polyamide may also provide a poly(amino1,3-oxazol) by intramolecular cyclization reactions or even lead to a greater degree of cyclization to construct a polymeric system based on the fused heterocyclic 1,3-oxazol and pyrrole due to secondary oxidative reactions (dehydrogenation). The formation of extender-conjugated linear polyamides through decyanogenation reactions may also be considered, in addition to the generation of cyclic polyamides, and it is thought that deamination processes could lead to the production of other N-heterocyclic conjugated macrostructures. This scheme presents oxidative reactions that were described by Ferris and Edelson concerning the condensation mechanism of cyanide to HCN oligomers [165]. To finish, these heterocyclic chains or segments can evolve through the continued elimination of $\mathrm{NH}_{3}$, causing the formation of fully graphitic $\mathrm{C}_{x} \mathrm{~N}_{y}(\mathrm{H})_{z}$, with $\mathrm{x}>\mathrm{y}>\mathrm{z}$, and layers, as indicated in the example as linked imidazole units (poly-aminoimidazole 2D, in the bottom left part of Scheme 4). This latter reaction is postulated in the sequence of polymerization reactions proposed for the synthesis of polymeric graphitic carbon nitride networks, $g$-CN, 
from different organic precursors, such as dicyandiamide, melamine, urea and related heterocyclic arenes [190].

However, it is important to recall that the AMN molecule is an $\mathrm{AB}_{2}$ monomer and that, as is well known in polymer chemistry, dendritic polymers can be obtained from this type of monomer. These dendritic polymers comprise both monodisperse dendrimers with exact branching and irregularly branched, polydisperse, hyperbranched polymers, among other architectures [191]. In contrast to the linear system proposed in Scheme 4, AMN enables non-linear growth. As a consequence, a highly branched scaffold can be obtained, and its size is defined by the number of generations $(G)$. This is exemplified in Scheme 6, which displays a G3 dendritic architecture. The first stage is raised by the addition of two AMN molecules over the two nitrile groups of this monomer, acting like the core. However, in the next stage, new additions are formulated on the imine groups due to their strong electrophilic character, giving G2 (15-mer). Successive additions, such as those proposed in the first stage, produce a new generation, G3 (39-mer), which can evolve through the intramolecular cyclizations previously described, leading to polyamine-containing aminocyano-imidazole rings. Logically, in competition with these intramolecular cyclizations, different elimination reactions (deamination and/or dehydro-cyanation) could take place simultaneously to obtain a more conjugated system, such as that obtained from the collateral reactions described in the previous schemes. In addition, hydrolytic reactions have not been considered in this case. This novel hyperbranched architecture for $\mathrm{HCN}$ polymers is in accordance with the conclusion achieved by Eastman et al. who explored their structures by phase contrast scanning force microscopy [163].

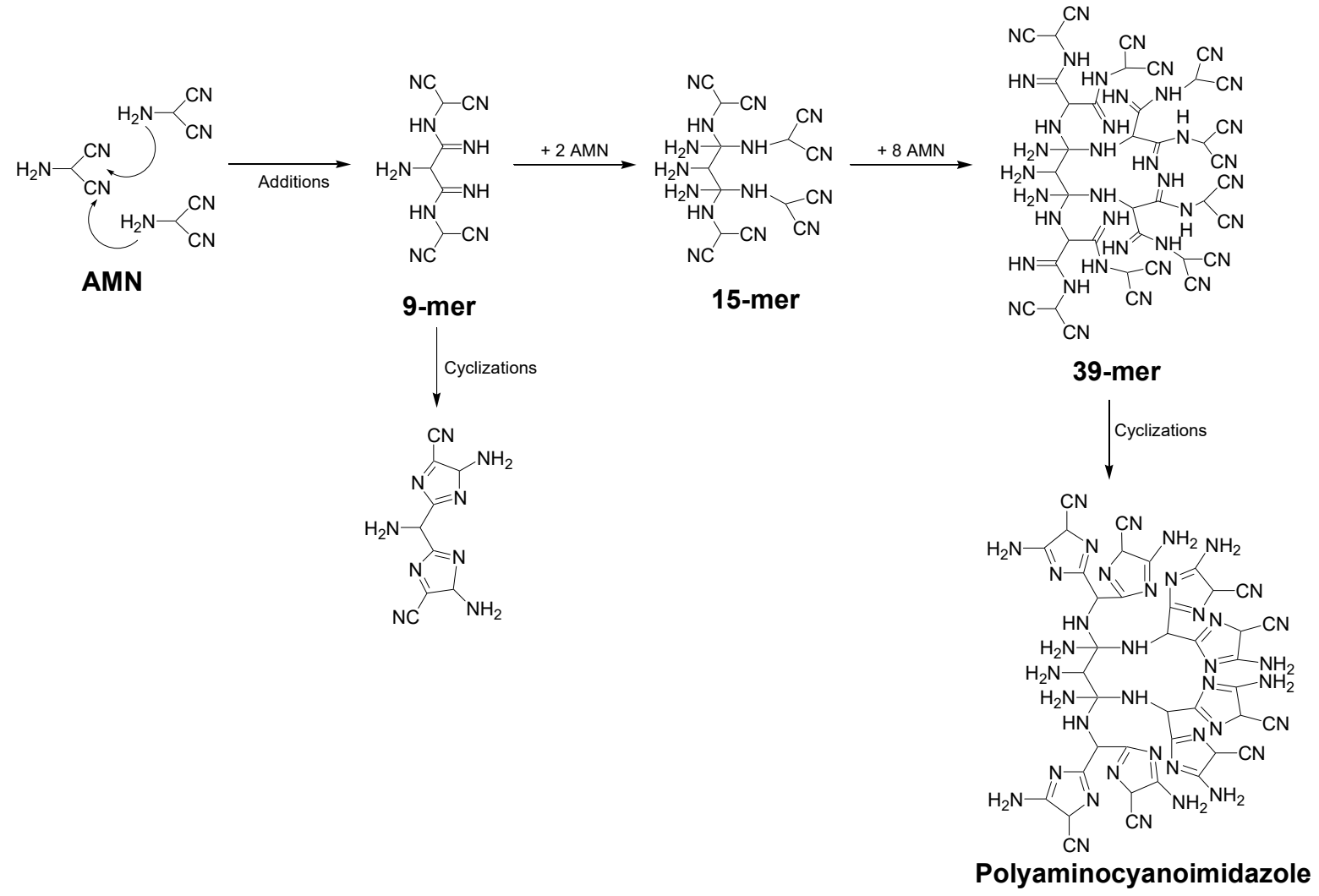

Scheme 6. Alternative hypothetical pathway for the formation of an HCN polymer from amino-nalono-nitrile (AMN) according to hyperbranched growth.

The last HCN-monomer considered is DAMN. This compound is a weakly basic amine, and its chemistry was explored in depth a long time ago. Thus, extensive use has been made of this convenient reagent for the preparation of heterocyclic molecules and polymers [192,193]. The use of DAMN also has great potential in different fields, such as in 
chemo-sensors for sensing ionic and neutral species [194] and as precursors of advanced functional materials $[117,195,196]$. DAMN is tetrasubstituted ethylene, and in this case, the first approach is a polymerization reaction based on the double bond $\mathrm{C}=\mathrm{C}$. Polymerizations involving olefin monomers are a major sector of polymer chemistry. Habitually, vinyl monomers contain one or two activating groups to facilitate the propagating reaction. If the two substituents are germinal, high reactivity results because of the dual stabilization of propagating radicals or ions. If the substituents are adjacent, lower reactivity is observed, and the second substituent cannot offer additional stabilization and interferes with steric hindrance. Little work has been reported on tri- and tetrasubstituted monomers, and a large part of the knowledge regarding the polymer chemistry of these compounds is due to the contributions of Hall and Padias [197]. It is possible to conclude that these highly substituted alkenes do not homopolymerize but copolymerize alternatingly with electron-rich co-monomers.

With this background, it is possible to propose an initial polymerization route based on the addition between amine groups of c-DAMN, the nucleophilic center, and the imine groups of its tautomer, the electrophilic core. The $\mathrm{C}=\mathrm{N}$ moiety exhibits electronwithdrawing properties, resembling those of the carbonyl groups; however, logically, this addition reaction is absolutely conditioned by imine-enamine tautomerism, which has been observed and measured for only a few isolated systems [198,199]. Therefore, a linear polyamine must be obtained, as shown in Scheme 5, particularized as a 12-mer. New, extended, conjugated macromolecular systems could be obtained from this polyamine by two subsequent elimination reactions, dehydro-cyano-genation (Pathway a) and deamination (Pathway b). It is important to note that both reactions have been recently verified in a work focused on the highly efficient melt polymerization of DAMN [167]. The subsequent formation of stable five- or six-membered rings is possible from both pathways. One pathway occurs through the so-called poly-amino-malononitrile or proto-peptide, as described in Scheme 2. In contrast, the other pathway allows the synthesis of a poly-aminopyrazine, which can yield a ladder structure based on this case in the pyrazine and pyrrole rings, similar to the previously mentioned corresponding poly-amino-imidazole. Again, hydrolysis reactions have not been considered to achieve simpler mechanistic schemes. However, this first route also presents oxidative reactions, which were postulated for the first time by Ferris and Edelson concerning the condensation mechanism of cyanide to HCN oligomers [165]. These authors indicated that DAMN condenses with additional HCN or possibly other DAMN molecules to provide oligomeric products. Redox reactions that take place during oligomerization yield reduced HCN oligomers and di-imino-succinonitrile. Di-imino-succino-nitrile is hydrolyzed to urea and oxalic acid, possibly through the formation of 2,3-dioxosuccinonitrile. Both derivatives may react with DAMN, and these reactions have been omitted in this scheme.

At this point, it is convenient to explain that the formation of macromolecular chains from DAMN occurs without the implicit participation of nitrile groups. Logically, the polymerization of nitriles must be considered. Route 2 shows the possible mechanism underlying the polymerization of DAMN by means of nitrile groups, according to the mechanism described in Route 2 in Scheme 4. The nucleophilic center of DAMN adds to the electrophilic carbon of the nitrile group of other molecules, followed by hydrogen shuffling to the nitrogen, forming the imine bond. In this case, the polyamine 16-mer can then undergo intramolecular cyclizations to produce a poly-aminoimidazole, with heterocycle rings linked by $=\mathrm{C}-\mathrm{NH}_{2}$ groups over the backbone, which can evolve according to the collateral reactions displayed in Scheme 4.

A third route can be proposed for DAMN. The initiation logically occurs by the amino group, but after a first addition nitrile polymerization takes place through a nucleophilic attack on the carbon atom of an adjacent nitrile group and induces it to cyclize, leading to the formation of a ladder polymer structure. This linear cyclopolymerization yields a poly-imino-diamino-pyrrole, which can result in a condensate macrostructure via the deamination reaction postulated herein. This mechanistic route has been described for 
other nitrile polymers, such as phthalonitrile resins. During their polymerization process, the phthalonitrile group tends to transform into phthalocyanine, triazine and iso-indoline units, and this mechanism ensures the formation of highly cross-linked and void-free polymer networks [200]. In addition to these three mechanisms of polymerization, DAMN is an $A_{2} B_{2}$ monomer, and the self-polycondensation of this type of compound has great potential applications in the synthesis of covalent organic frameworks; therefore, other possible 2D architectures could be considered [201].

\section{Conclusions and Outlooks}

$\mathrm{HCN}$ chemistry has been comprehensively revised considering its traditional high interest for several fields, such as prebiotic chemistry, astrobiology and cosmochemistry, as well as taking into account recent possibilities for the design and development of new and advanced functional materials. It has been clearly shown that the synthetic conditions have a significant influence on the final properties of $\mathrm{HCN}$-derived polymers. Nevertheless, we are still far from a fundamental understanding of the underlying structure-property relationships of this singular and complex system, which might form the basis for a "molecular engineering" approach to electronic, optoelectronic, and photonic polymers. This is due to their intractability and insolubility in organic solvents, which impede the appropriate characterization of their molecular structure and physical properties as well as exploration of their applications. These conclusive facts open a broad area of research into new insights regarding either chemical evolution or materials and surface science.

Author Contributions: Conceptualization, writing-original draft preparation and supervision, M.R.-B.; writing-review and editing, J.L.d.l.F.; writing and editing, C.P.-F.; review-supervision and funding acquisition, E.M.-M. All authors have read and agreed to the published version of the manuscript.

Funding: This research was funded by the projects PID2019-104205GB-C21 and PID2019-107442RBC32 from the Spanish Ministerio de Ciencia, Innovación y Universidades and by the Spanish State Research Agency (AEI) project MDM-2017-0737 Centro de Astrobiología (CSIC-INTA), Unidad de Excelencia María de Maeztu.

Acknowledgments: M.R.-B., C.P.F. and E.M.-M. used the research facilities of the Centro de Astrobiología (CSIC-INTA) and were supported by the Instituto Nacional de Técnica Aeroespacial "Esteban Terradas" (INTA) and by the Spanish State Research Agency (AEI) Centro de Astrobiología (CSIC-INTA), Unidad de Excelencia María de Maeztu. J.L.F. was supported by the Instituto Nacional de Técnica Aeroespacial "Esteban Terradas" (INTA). C.P.F. Ph-D MINECO financial support reference PRE2018-085781.

Conflicts of Interest: The authors declare no conflict of interest.

\section{References}

1. Bacchus-Montabonel, M.-C. Theoretical Investigation of Proton Collisions on Prebiotic Candidates: Hydrogen Cyanide Polymers. Phys. Chem. Chem. Phys. 2017, 19, 19566-19572. [CrossRef]

2. Rannou, P.; West, R. Supersaturation on Pluto and Elsewhere. Icarus 2018, 312, 36-44. [CrossRef]

3. Hänni, N.; Altwegg, K.; Pestoni, B.; Rubin, M.; Schroeder, I.; Schuhmann, M.; Wampfler, S. First in Situ Detection of the CN Radical in Comets and Evidence for a Distributed Source. Mon. Not. R. Astron. Soc. 2020, 498, 2239-2248. [CrossRef]

4. Mandt, K.; Luspay-Kuti, A.; Hamel, M.; Jessup, K.-L.; Hue, V.; Kammer, J.; Filwett, R. Photochemistry on Pluto: Part II HCN and Nitrogen Isotope Fractionation. Mon. Not. R. Astron. Soc. 2017, 472, 118-128. [CrossRef] [PubMed]

5. Wirström, E.S.; Charnley, S.B. Revised Models of Interstellar Nitrogen Isotopic Fractionation. Mon. Not. R. Astron. Soc. 2018, 474, 3720-3726. [CrossRef]

6. Pearce, B.K.D.; Molaverdikhani, K.; Pudritz, R.E.; Henning, T.; Hébrard, E. HCN Production in Titan's Atmosphere: Coupling Quantum Chemistry and Disequilibrium Atmospheric Modeling. Astrophys. J. 2020, 901, 110. [CrossRef]

7. Hill, R.D. An Efficient Lightning Energy Source on the Early Earth. Orig. Life Evol. Biosph. 1992, 22, 277-285. [CrossRef] [PubMed]

8. Holm, N.G.; Neubeck, A. Reduction of Nitrogen Compounds in Oceanic Basement and Its Implications for HCN Formation and Abiotic Organic Synthesis. Geochem. Trans. 2009, 10, 9. [CrossRef] [PubMed]

9. Huber, C.; Kraus, F.; Hanzlik, M.; Eisenreich, W.; Wächtershäuser, G. Elements of Metabolic Evolution. Chem. Eur. J. 2012, 18, 2063-2080. [CrossRef] [PubMed] 
10. Ferus, M.; Kubelík, P.; Knížek, A.; Pastorek, A.; Sutherland, J.; Civiš, S. High Energy Radical Chemistry Formation of HCN-Rich Atmospheres on Early Earth. Sci. Rep. 2017, 7, 6275. [CrossRef] [PubMed]

11. Airapetian, V.S.; Glocer, A.; Gronoff, G.; Hébrard, E.; Danchi, W. Prebiotic Chemistry and Atmospheric Warming of Early Earth by an Active Young Sun. Nat. Geosci. 2016, 9, 452-455. [CrossRef]

12. Matthews, C.N. Dark Matter in the Solar System: Hydrogen Cyanide Polymers. Orig. Life Evol. Biosph. 1991, $21,421-434$. [CrossRef]

13. Matthews, C.N. Hydrogen Cyanide Polymers: From Laboratory to Space. Planet. Space Sci. 1995, 43, 1365-1370. [CrossRef]

14. Bauer, H. Die Ersten Organisch-Chemischen Synthesen. Naturwissenschaften 1980, 67, 1-6. [CrossRef]

15. Proust, J.L. Gehlen's J. Chem. Physik, 3, 384; 1806. Ann. Chim. Physique 1807, 60, 233.

16. Wippermann, R. Ueber Tricyanwasserstoff, Eine Der Blausäure Polymere Verbindung. Eur. J. Inorg. Chem. 1874, 7, 767-772. [CrossRef]

17. Pflüger, E. Nachtrag zu meinem Aufsatz: Ueber die physiologische Verbrennung in den lebendigen Organismen. Pflüger Arch. 1875, 10, 641-644. [CrossRef]

18. Oró, J. Synthesis of Adenine from Ammonium Cyanide. Biochem. Biophys. Res. Commun. 1960, 2, 407-412. [CrossRef]

19. Patel, B.H.; Percivalle, C.; Ritson, D.J.; Duffy, C.D.; Sutherland, J.D. Common Origins of RNA, Protein and Lipid Precursors in a Cyanosulfidic Protometabolism. Nat. Chem. 2015, 7, 301-307. [CrossRef]

20. Eschenmoser, A. On a Hypothetical Generational Relationship between HCN and Constituents of the Reductive Citric Acid Cycle. Chem. Biodiver. 2007, 4, 554-573. [CrossRef] [PubMed]

21. Eschenmoser, A. The Search for the Chemistry of Life's Origin. Tetrahedron 2007, 63, 12821-12844. [CrossRef]

22. Das, T.; Ghule, S.; Vanka, K. Insights into the Origin of Life: Did It Begin from HCN and $\mathrm{H}_{2} \mathrm{O}$ ? ACS Cent. Sci. 2019, 5, 1532-1540. [CrossRef] [PubMed]

23. Ruiz-Bermejo, M.; Zorzano, M.-P.; Osuna-Esteban, S. Simple Organics and Biomonomers Identified in HCN Polymers: An Overview. Life 2013, 3, 421-448. [CrossRef] [PubMed]

24. Yadav, M.; Kumar, R.; Krishnamurthy, R. Chemistry of Abiotic Nucleotide Synthesis. Chem. Rev. 2020, 120, 4766-4805. [CrossRef] [PubMed]

25. Sanchez, R.; Ferris, J.; Orgel, L.E. Conditions for Purine Synthesis: Did Prebiotic Synthesis Occur at Low Temperatures? Science 1966, 153, 72-73. [CrossRef] [PubMed]

26. Sanchez, R.A.; Ferris, J.P.; Orgel, L.E. Studies in Prebiodc Synthesis: II. Synthesis of Purine Precursors and Amino Acids from Aqueous Hydrogen Cyanide. J. Mol. Biol. 1967, 30, 223-253.

27. Ferris, J.P.; Donner, D.B.; Lobo, A.P. Possible Role of Hydrogen Cyanide in Chemical Evolution: The Oligomerization and Condensation of Hydrogen Cyanide. J. Mol. Biol. 1973, 74, 511-518. [CrossRef]

28. Ferris, J.P.; Wos, J.D.; Ryan, T.J.; Lobo, A.P.; Donner, D.B. Biomolecules from HCN. Orig. Life 1974, 5, 153-157. [CrossRef]

29. Ferris, J.P.; Joshi, P.C.; Lawless, J.G. Chemical Evolution XXIX. Pyrimidines from Hydrogen Cyanide. BioSystems 1977, 9, 81-86. [CrossRef]

30. Ferris, J.P.; Joshi, P.C.; Edelson, E.H.; Lawless, J.G. HCN: A Plausible Source of Purines, Pyrimidines and Amino Acids on the Primitive Earth. J. Mol. Evol. 1978, 11, 293-311. [CrossRef] [PubMed]

31. Ferris, J.P.; Hagan, W.J., Jr. HCN and Chemical Evolution: The Possible Role of Cyano Compounds in Prebiotic Synthesis. Tetrahedron 1984, 40, 1093-1120. [CrossRef]

32. Schwartz, A.W.; Joosten, H.; Voet, A.B. Prebiotic Adenine Synthesis via HCN Oligomerization in Ice. Biosystems 1982, 15, $191-193$. [CrossRef]

33. Voet, A.B.; Schwartz, A.W. Uracil Synthesis via HCN Oligomerization. Orig. Life 1982, 12, 45-49. [CrossRef] [PubMed]

34. Schwartz, A.W.; Goverde, M. Acceleration of HCN Oligomerization by Formaldehyde and Related Compounds: Implications for Prebiotic Syntheses. J. Mol. Evol. 1982, 18, 351-353. [CrossRef] [PubMed]

35. Voet, A.B.; Schwartz, A.W. Prebiotic Adenine Synthesis from HCN_Evidence for a Newly Discovered Major Pathway. Bioorg. Chem. 1983, 12, 8-17. [CrossRef]

36. Schwartz, A.W.; Voet, A.B.; Van der Veen, M. Recent Progress in the Prebiotic Chemistry of HCN. Orig. Life 1984, 14, 91-98. [CrossRef]

37. Schwartz, A.W.; Bakker, C.G. Was Adenine the First Purine? Science 1989, 245, 1102-1104. [CrossRef] [PubMed]

38. Miyakawa, S.; Cleaves, H.J.; Miller, S.L. The Cold Origin of Life: B. Implications Based on Pyrimidines and Purines Produced from Frozen Ammonium Cyanide Solutions. Orig. Life Evol. Biosph. 2002, 32, 209-218. [CrossRef] [PubMed]

39. Levy, M.; Miller, S.L.; Brinton, K.; Bada, J.L. Prebiotic Synthesis of Adenine and Amino Acids under Europa-like Conditions. Icarus 2000, 145, 609-613. [CrossRef]

40. da Silva, J.B.P.; de Araujo, A.P.M. A New Mechanism of Guanine-Isomer Formation from Species Previously Observed in the Interstellar Medium. ACS Earth Space Chem. 2017, 1, 376-383. [CrossRef]

41. Gupta, V.P.; Tandon, P.; Rawat, P.; Singh, R.N.; Singh, A. Quantum Chemical Study of a New Reaction Pathway for the Adenine Formation in the Interstellar Space. Astron. Astrophys. 2011, 528, A129. [CrossRef]

42. Jung, S.H.; Choe, J.C. Mechanisms of Prebiotic Adenine Synthesis from HCN by Oligomerization in the Gas Phase. Astrobiology 2013, 13, 465-475. [CrossRef] 
43. Oró, J.; Kimball, A.P. Synthesis of Purines under Possible Primitive Earth Conditions. I. Adenine from Hydrogen Cyanide. Arch. Biochem. Biophys. 1961, 94, 217-227. [CrossRef]

44. Oro, J.; Kamat, S.S. Amino-Acid Synthesis from Hydrogen Cyanide under Possible Primitive Earth Conditions. Nature 1961, 190, 442-443. [CrossRef] [PubMed]

45. Lowe, C.U.; Rees, M.W.; Markham, R. Synthesis of Complex Organic Compounds from Simple Precursors: Formation of Amino-Acids, Amino-Acid Polymers, Fatty Acids and Purines from Ammonium Cyanide. Nature 1963, 199, 219-222. [CrossRef]

46. Abelson, P.H. Chemical Events on the Primitive Earth. Proc. Natl. Acad. Sci. USA 1966, 55, 1365-1372. [CrossRef]

47. Matthews, C.N.; Moser, R.E. Peptide Synthesis from Hydrogen Cyanide and Water. Nature 1967, 215, 1230-1234. [CrossRef] [PubMed]

48. Ferris, J.P.; Wos, J.D.; Nooner, D.W.; Oró, J. Chemical Evolution. J. Mol. Evol. 1974, 3, 225-231. [CrossRef] [PubMed]

49. Ferris, J.P.; Wos, J.D.; Lobo, A.P. Chemical Evolution. J. Mol. Evol. 1974, 3, 311-316. [CrossRef] [PubMed]

50. Marín-Yaseli, M.R.; Mompeán, C.; Ruiz-Bermejo, M. A Prebiotic Synthesis of Pterins. Chem. Eur. J. 2015, 21, 13531-13534. [CrossRef]

51. Marín-Yaseli, M.R.; González-Toril, E.; Mompeán, C.; Ruiz-Bermejo, M. The Role of Aqueous Aerosols in the “Glyoxylate Scenario": An Experimental Approach. Chem. Eur. J. 2016, 22, 12785-12799. [CrossRef]

52. Hortal, L.; Pérez-Fernández, C.; de la Fuente, J.L.; Valles, P.; Mateo-Martí, E.; Ruiz-Bermejo, M. A Dual Perspective on the Microwave-Assisted Synthesis of HCN Polymers towards the Chemical Evolution and Design of Functional Materials. Sci. Rep. 2020, 10, 22350. [CrossRef] [PubMed]

53. Negrón-Mendoza, A.; Draganić, Z.D.; Navarro-González, R.; Draganić, I.G. Aldehydes, Ketones, and Carboxylic Acids Formed Radiolytically in Aqueous Solutions of Cyanides and Simple Nitriles. Radiat. Res. 1983, 95, 248-261. [CrossRef]

54. Negrón-Mendoza, A.; Draganić, Z.D. Search for Heterocyclic Radiolytic Products in Aqueous Solutions of Cyanides. Adv. Space Res. 1984, 4, 121-124. [CrossRef]

55. Negrón-Mendoza, A.; Ramos-Bernal, S.; Cruz, E.; Juárez, J.M. Radiolysis of HCN in Heterogeneous Phase. Radiat. Phys. Chem. 2001, 61, 771-772. [CrossRef]

56. Yi, R.; Tran, Q.P.; Ali, S.; Yoda, I.; Adam, Z.R.; Cleaves, H.J.; Fahrenbach, A.C. A Continuous Reaction Network That Produces RNA Precursors. Proc. Natl. Acad. Sci. USA 2020, 117, 13267-13274. [CrossRef]

57. Yi, R.; Hongo, Y.; Yoda, I.; Adam, Z.R.; Fahrenbach, A.C. Radiolytic Synthesis of Cyanogen Chloride, Cyanamide and Simple Sugar Precursors. Chem. Sel. 2018, 3, 10169-10174. [CrossRef]

58. Ritson, D.; Sutherland, J.D. Prebiotic Synthesis of Simple Sugars by Photoredox Systems Chemistry. Nat. Chem. 2012, 4, 895-899. [CrossRef] [PubMed]

59. Xu, J.; Ritson, D.J.; Ranjan, S.; Todd, Z.R.; Sasselov, D.D.; Sutherland, J.D. Photochemical Reductive Homologation of Hydrogen Cyanide Using Sulfite and Ferrocyanide. Chem. Comm. 2018, 54, 5566-5569. [CrossRef]

60. Sutherland, J.D. The Origin of Life-Out of the Blue. Angew. Chem. Int. Ed. 2016, 55, 104-121. [CrossRef]

61. Labadie, M.; Jensen, R.; Neuzil, E. Recherches sur l'évolution pré-biologique III. Les acides azulmiques noirs formés à partir du cyanure d'ammonium. Biochim. et Biophys. Acta Gen. Subj. 1968, 165, 525-533. [CrossRef]

62. Ghoshal, S.; Pramanik, A.; Sarkar, P. Theoretical Investigations on the Possibility of Prebiotic HCN Formation via O-Addition Reactions. J. Phys. Chem. A 2020, 124, 4782-4792. [CrossRef] [PubMed]

63. Rimmer, P.B.; Ferus, M.; Waldmann, I.P.; Knížek, A.; Kalvaitis, D.; Ivanek, O.; Kubelík, P.; Yurchenko, S.N.; Burian, T.; Dostál, J.; et al. Identifiable Acetylene Features Predicted for Young Earth-like Exoplanets with Reducing Atmospheres Undergoing Heavy Bombardment. Astrophys. J. 2019, 888, 21. [CrossRef]

64. Ghoshal, S.; Pramanik, A.; Biswas, S.; Sarkar, P. CH3NO as a Potential Intermediate for Early Atmospheric HCN: A Quantum Chemical Insight. Phys. Chem. Chem. Phys. 2019, 21, 25126-25138. [CrossRef]

65. Parkos, D.; Pikus, A.; Alexeenko, A.; Melosh, H.J. HCN Production via Impact Ejecta Reentry During the Late Heavy Bombardment. J. Geophys. Res. Planets 2018, 123, 892-909. [CrossRef]

66. Rimmer, P.B.; Shorttle, O. Origin of Life's Building Blocks in Carbon- and Nitrogen-Rich Surface Hydrothermal Vents. Life 2019, 9 , 12. [CrossRef]

67. Maruyama, S.; Kurokawa, K.; Ebisuzaki, T.; Sawaki, Y.; Suda, K.; Santosh, M. Nine Requirements for the Origin of Earth's Life: Not at the Hydrothermal Vent, but in a Nuclear Geyser System. Geosci. Front. 2019, 10, 1337-1357. [CrossRef]

68. Marín-Yaseli, M.R.; González-Toril, E.; Ruiz-Bermejo, M. Reactivity of Cyanide at Water-Ice Interfaces: Implications for the Search for Organics on Icy Worlds. Front. Astron. Space Sci. 2020, 7, 519017. [CrossRef]

69. Kulp, T.R.; Hoeft, S.E.; Miller, L.G.; Saltikov, C.; Murphy, J.N.; Han, S.; Lanoil, B.; Oremland, R.S. Dissimilatory Arsenate and Sulfate Reduction in Sediments of Two Hypersaline, Arsenic-Rich Soda Lakes: Mono and Searles Lakes, California. Appl. Environ. Microbiol. 2006, 72, 6514-6526. [CrossRef] [PubMed]

70. Visscher, P.T.; Gallagher, K.L.; Bouton, A.; Farias, M.E.; Kurth, D.; Sancho-Tomás, M.; Philippot, P.; Somogyi, A.; Medjoubi, K.; Vennin, E.; et al. Modern Arsenotrophic Microbial Mats Provide an Analogue for Life in the Anoxic Archean. Commun. Earth Environ. 2020, 1, 1-10. [CrossRef]

71. Sancho-Tomás, M.; Somogyi, A.; Medjoubi, K.; Bergamaschi, A.; Visscher, P.T.; van Driessche, A.E.S.; Gérard, E.; Farias, M.E.; Contreras, M.; Philippot, P. Geochemical Evidence for Arsenic Cycling in Living Microbialites of a High Altitude Andean Lake (Laguna Diamante, Argentina). Chem. Geol. 2020, 549, 119681. [CrossRef] 
72. Toner, J.D.; Catling, D.C. Alkaline Lake Settings for Concentrated Prebiotic Cyanide and the Origin of Life. Geochim. Cosmochim. Acta 2019, 260, 124-132. [CrossRef]

73. Villafañe-Barajas, S.A.; Colín-García, M.; Negrón-Mendoza, A.; Ruiz-Bermejo, M. An Experimental Study of the Thermolysis of Hydrogen Cyanide: The Role of Hydrothermal Systems in Chemical Evolution. Int. J. Astrobiol. 2020, 19, 369-378. [CrossRef]

74. Villafañe-Barajas, S.A.; Ruiz-Bermejo, M.; Rayo-Pizarroso, P.; Colín-García, M. Characterization of HCN-Derived Thermal Polymer: Implications for Chemical Evolution. Processes 2020, 8, 968. [CrossRef]

75. Ruiz-Bermejo, M.; Menor-Salván, C.; Osuna-Esteban, S.; Veintemillas-Verdaguer, S. The Effects of Ferrous and Other Ions on the Abiotic Formation of Biomolecules Using Aqueous Aerosols and Spark Discharges. Orig. Life Evol. Biosph. 2007, 37, 507-521. [CrossRef] [PubMed]

76. Mukhin, L. Evolution of Organic Compounds in Volcanic Regions. Nature 1974, 251, 50-51. [CrossRef]

77. Mukhin, L.; Bondarev, V.B.; Safanova, E.N. The Role of Volcanic Processes in the Evolution of Organic Compounds on the Primitive Earth. Mod. Geol. 1978, 6, 119-122.

78. Ruiz-Bermejo, M.; Osuna-Esteban, S.; Zorzano, M.-P. Role of Ferrocyanides in the Prebiotic Synthesis of $\alpha$-Amino Acids. Orig. Life Evol. Biosph. 2013, 43, 191-206. [CrossRef]

79. Bolm, C.; Mocci, R.; Schumacher, C.; Turberg, M.; Puccetti, F.; Hernández, J.G. Mechanochemical Activation of Iron Cyano Complexes: A Prebiotic Impact Scenario for the Synthesis of $\alpha$-Amino Acid Derivatives. Angew. Chem. Int. Ed. 2018, 57, 2423-2426. [CrossRef]

80. Ruiz-Bermejo, M.; Rogero, C.; Menor-Salván, C.; Osuna-Esteban, S.; Martín-Gago, J.Á.; Veintemillas-Verdaguer, S. Thermal Wet Decomposition of Prussian Blue: Implications for Prebiotic Chemistry. Chem. Biodiver. 2009, 6, 1309-1322. [CrossRef]

81. Sharma, R.; Iqubal, M.A.; Kamaluddin. Possible Role of Prussian Blue Nanoparticles in Chemical Evolution: Interaction with Ribose Nucleotides. Int. J. Astrobiol. 2016, 15, 17-25. [CrossRef]

82. Burcar, B.; Castañeda, A.; Lago, J.; Daniel, M.; Pasek, M.A.; Hud, N.V.; Orlando, T.M.; Menor-Salván, C. A Stark Contrast to Modern Earth: Phosphate Mineral Transformation and Nucleoside Phosphorylation in an Iron- and Cyanide-Rich Early Earth Scenario. Angew. Chem. Int. Ed. 2019, 58, 16981-16987. [CrossRef]

83. Boclair, J.W.; Braterman, P.S.; Brister, B.D.; Jiang, J.; Lou, S.; Wang, Z.; Yarberry, F. Cyanide Self-Addition, Controlled Adsorption, and Other Processes at Layered Double Hydroxides. Orig. Life Evol. Biosph. 2001, 31, 53-69. [CrossRef]

84. Colin-Garcia, M.; Heredia, A.; Negron-Mendoza, A.; Ortega, F.; Pi, T.; Ramos-Bernal, S. Adsorption of HCN onto Sodium Montmorillonite Dependent on the PH as a Component to Chemical Evolution. Int. J. Astrobiol. 2014, 13, 310-318. [CrossRef]

85. Ferris, J.P.; Edelson, E.H.; Mount, N.M.; Sullivan, A.E. The Effect of Clays on the Oligomerization of HCN. J. Mol. Evol. 1979, 13, 317-330. [CrossRef] [PubMed]

86. Ferris, J.P.; Hagan, W.J.; Alwis, K.W.; McCrea, J. Chemical Evolution Clay-Mediated Oxidation of Diaminomaleonitrile. J. Mol. Evol. 1982, 18, 304-309. [CrossRef] [PubMed]

87. Ruiz-Bermejo, M.; Menor-Salván, C.; Zorzano, M.-P.; El-Hachemi, Z.; Osuna-Esteban, S.; Veintemillas-Verdaguer, S. Water interfacial processes in prebiotic chemistry. In Astrobiology: Physical Origin, Biological Evolution and Spatial Distribution; Hegedus, S., Csonka, J., Eds.; Nova Science Publishers Inc.: New York, NY, USA, 2009.

88. Griffith, E.C.; Tuck, A.F.; Vaida, V. Ocean-Atmosphere Interactions in the Emergence of Complexity in Simple Chemical Systems. Acc. Chem. Res. 2012, 45, 2106-2113. [CrossRef] [PubMed]

89. Fábián, B.; Szőri, M.; Jedlovszky, P. Floating Patches of HCN at the Surface of Their Aqueous Solutions-Can They Make "HCN World" Plausible? J. Phys. Chem. C 2014, 118, 21469-21482. [CrossRef]

90. Matthews, C.N.; Minard, R.D. Hydrogen Cyanide Polymers, Comets and the Origin of Life. Faraday Discuss. 2006, $133,393-401$. [CrossRef] [PubMed]

91. Quirico, E.; Szopa, C.; Cernogora, G.; Lees, V.; Derenne, S.; McMillan, P.F.; Montagnac, G.; Reynard, B.; Rouzaud, J.-N.; Fray, N.; et al. Tholins and Their Relevance for Astrophysical Issues. Proc. Int. Astron. Union 2008, 4, 409-416. [CrossRef]

92. Matthews, C.N.; Minard, R.D. Hydrogen Cyanide Polymers Connect Cosmochemistry and Biochemistry. Proc. Int. Astron. Union 2008, 4, 453-458. [CrossRef]

93. Fray, N.; Bénilan, Y.; Cottin, H.; Gazeau, M.-C.; Minard, R.D.; Raulin, F. Experimental Study of the Degradation of Polymers: Application to the Origin of Extended Sources in Cometary Atmospheres. Meteorit. Planet. Sci. 2004, 39, 581-587. [CrossRef]

94. Bonnet, J.-Y.; Quirico, E.; Buch, A.; Thissen, R.; Szopa, C.; Carrasco, N.; Cernogora, G.; Fray, N.; Cottin, H.; Roy, L.L.; et al. Formation of Analogs of Cometary Nitrogen-Rich Refractory Organics from Thermal Degradation of Tholin and HCN Polymer. Icarus 2015, 250, 53-63. [CrossRef]

95. Todd, Z.R.; Öberg, K.I. Cometary Delivery of Hydrogen Cyanide to the Early Earth. Astrobiology 2020, 20, 1109-1120. [CrossRef] [PubMed]

96. Smith, K.E.; House, C.H.; Arevalo, R.D.; Dworkin, J.P.; Callahan, M.P. Organometallic Compounds as Carriers of Extraterrestrial Cyanide in Primitive Meteorites. Nat. Commun. 2019, 10, 2777. [CrossRef]

97. Ferus, M.; Rimmer, P.; Cassone, G.; Knížek, A.; Civiš, S.; Šponer, J.E.; Ivanek, O.; Šponer, J.; Saeidfirozeh, H.; Kubelík, P.; et al. One-Pot Hydrogen Cyanide-Based Prebiotic Synthesis of Canonical Nucleobases and Glycine Initiated by High-Velocity Impacts on Early Earth. Astrobiology 2020, 20, 1476-1488. [CrossRef] [PubMed] 
98. Dinelli, B.M.; Puertas, M.L.; Fabiano, F.; Adriani, A.; Moriconi, M.L.; Funke, B.; García-Comas, M.; Oliva, F.; D'Aversa, E.; Filacchione, G. Climatology of $\mathrm{CH} 4, \mathrm{HCN}$ and $\mathrm{C}_{2} \mathrm{H}_{2}$ in Titan's Upper Atmosphere from Cassini/VIMS Observations. Icarus 2019, 331, 83-97. [CrossRef]

99. Lebonnois, S.; Bakes, E.L.O.; McKay, C.P. Transition from Gaseous Compounds to Aerosols in Titan's Atmosphere. Icarus 2002, 159, 505-517. [CrossRef]

100. Khare, B.N.; Sagan, C.; Thompson, W.R.; Arakawa, E.T.; Meisse, C.; Tuminello, P.S. Optical Properties of Poly-HCN and Their Astronomical Applications. Can. J. Chem. 1994, 72, 678-694. [CrossRef] [PubMed]

101. Budil, D.E.; Roebber, J.L.; Liebman, S.A.; Matthews, C.N. Multifrequency Electron Spin Resonance Detection of Solid-State Organic Free Radicals in HCN Polymer and a Titan Tholin. Astrobiology 2003, 3, 323-329. [CrossRef] [PubMed]

102. Vuitton, V.; Bonnet, J.-Y.; Frisari, M.; Thissen, R.; Quirico, E.; Dutuit, O.; Schmitt, B.; Roy, L.L.; Fray, N.; Cottin, H.; et al. Very High Resolution Mass Spectrometry of HCN Polymers and Tholins. Faraday Discuss. 2010, 147, 495-508. [CrossRef]

103. Rahm, M.; Lunine, J.I.; Usher, D.A.; Shalloway, D. Polymorphism and Electronic Structure of Polyimine and Its Potential Significance for Prebiotic Chemistry on Titan. Proc. Natl. Acad. Sci. USA 2016, 113, 8121-8126. [CrossRef]

104. Ennis, C.; Cable, M.L.; Hodyss, R.; Maynard-Casely, H.E. Mixed Hydrocarbon and Cyanide Ice Compositions for Titan's Atmospheric Aerosols: A Ternary-Phase Co-Crystal Predicted by Density Functional Theory. ACS Earth Space Chem. 2020, 4, 1195-1200. [CrossRef]

105. Wilson, P.D.; Sagan, C. Spectrophotometry and Organic Matter on Iapetus: Composition Models. J. Geophys. Res. Planets 1995, 100, 7531-7537. [CrossRef] [PubMed]

106. Brucato, J.R.; Migliorini, A.; Barucci, M.A.; Carvano, J.M.; Dotto, E.; Mennella, V. Reflectance Spectra of Titan Tholin between 7000 and 10 Cm-1-Interpretation of Cassini/CIRS Observation of Saturn's Satellite Phoebe. Astron. Astrophys. 2010, 516, A92. [CrossRef]

107. Jeilani, Y.A.; Williams, P.N.; Walton, S.; Nguyen, M.T. Unified Reaction Pathways for the Prebiotic Formation of RNA and DNA Nucleobases. Phys. Chem. Chem. Phys. 2016, 18, 20177-20188. [CrossRef]

108. Rimmer, P.B.; Rugheimer, S. Hydrogen Cyanide in Nitrogen-Rich Atmospheres of Rocky Exoplanets. Icarus 2019, 329, $124-131$. [CrossRef]

109. Gerakines, P.A.; Moore, M.H.; Hudson, R.L. Ultraviolet Photolysis and Proton Irradiation of Astrophysical Ice Analogs Containing Hydrogen Cyanide. Icarus 2004, 170, 202-213. [CrossRef]

110. Saladino, R.; Di Mauro, E.; García-Ruiz, J.M. A Universal Geochemical Scenario for Formamide Condensation and Prebiotic Chemistry. Chem. Eur. J. 2019, 25, 3181-3189. [CrossRef]

111. Enchev, V.; Angelov, I.; Dincheva, I.; Stoyanova, N.; Slavova, S.; Rangelov, M.; Markova, N. Chemical Evolution: From Formamide to Nucleobases and Amino Acids without the Presence of Catalyst. J. Biomol. Struct. Dyn. 2020, 1-16. [CrossRef]

112. Menor-Salván, C. From the Dawn of Organic Chemistry to Astrobiology: Urea as a Foundational Component in the Origin of Nucleobases and Nucleotides. In Prebiotic Chemistry and Chemical Evolution of Nucleic Acids; Springer International Publishing: Cham, Switzerland, 2018; pp. 85-142. [CrossRef]

113. Menor-Salván, C.; Ruiz-Bermejo, D.M.; Guzmán, M.I.; Osuna-Esteban, S.; Veintemillas-Verdaguer, S. Synthesis of Pyrimidines and Triazines in Ice: Implications for the Prebiotic Chemistry of Nucleobases. Chem. Eur. J. 2009, 15, 4411-4418. [CrossRef] [PubMed]

114. d'Ischia, M.; Manini, P.; Moracci, M.; Saladino, R.; Ball, V.; Thissen, H.; Evans, R.A.; Puzzarini, C.; Barone, V. Astrochemistry and Astrobiology: Materials Science in Wonderland? Int. J. Mol. Sci. 2019, 20, 4079. [CrossRef] [PubMed]

115. He, C.; Lin, G.; Upton, K.T.; Imanaka, H.; Smith, M.A. Structural Investigation of HCN Polymer Isotopomers by Solution-State Multidimensional NMR. J. Phys. Chem. A 2012, 116, 4751-4759. [CrossRef] [PubMed]

116. Zhou, X.; Fang, Y.; Su, Y.; Ge, C.; Jin, B.; Li, Z.; Wu, S. Preparation and Characterization of Poly-Hydrogen Cyanide Nanofibers with High Visible Light Photocatalytic Activity. Catal. Commun. 2014, 46, 197-200. [CrossRef]

117. Ruiz-Bermejo, M.; de la Fuente, J.L.; Carretero-González, J.; García-Fernández, L.; Aguilar, M.R. A Comparative Study on HCN Polymers Synthesized by Polymerization of $\mathrm{NH}_{4} \mathrm{CN}$ or Diaminomaleonitrile in Aqueous Media: New Perspectives for Prebiotic Chemistry and Materials Science. Chem. Eur. J. 2019, 25, 11437-11455. [CrossRef]

118. Mas, I.; de la Fuente, J.L.; Ruiz-Bermejo, M. Temperature Effect on Aqueous $\mathrm{NH}_{4} \mathrm{CN}$ Polymerization: Relationship between Kinetic Behaviour and Structural Properties. Eur. Polym. J. 2020, 132, 109719. [CrossRef]

119. Inagaki, M.; Tsumura, T.; Kinumoto, T.; Toyoda, M. Graphitic Carbon Nitrides $\left(\mathrm{g}_{-} \mathrm{C}_{3} \mathrm{~N}_{4}\right)$ with Comparative Discussion to Carbon Materials. Carbon 2019, 141, 580-607. [CrossRef]

120. Thissen, H.; Evans, R.A.; Ball, V. Films and Materials Derived from Aminomalononitrile. Processes 2021, 9, 82. [CrossRef]

121. Lee, H.; Dellatore, S.M.; Miller, W.M.; Messersmith, P.B. Mussel-Inspired Surface Chemistry for Multifunctional Coatings. Science 2007, 318, 426-430. [CrossRef]

122. Thissen, H.; Koegler, A.; Salwiczek, M.; Easton, C.D.; Qu, Y.; Lithgow, T.; Evans, R.A. Prebiotic-Chemistry Inspired Polymer Coatings for Biomedical and Material Science Applications. NPG Asia Mater. 2015, 7, e225. [CrossRef]

123. Ball, V.; Toh, R.J.; Voelcker, N.H.; Thissen, H.; Evans, R.A. Electrochemical Deposition of Aminomalonitrile Based Films. Colloids Surf. A Physicochem. Eng. Asp. 2018, 552, 124-129. [CrossRef]

124. Menzies, D.J.; Ang, A.; Thissen, H.; Evans, R.A. Adhesive Prebiotic Chemistry Inspired Coatings for Bone Contacting Applications. ACS Biomater. Sci. Eng. 2017, 3, 793-806. [CrossRef] 
125. Chen, W.-H.; Liao, T.-Y.; Thissen, H.; Tsai, W.-B. One-Step Aminomalononitrile-Based Coatings Containing Zwitterionic Copolymers for the Reduction of Biofouling and the Foreign Body Response. ACS Biomater. Sci. Eng. 2019, 5, 6454-6462. [CrossRef] [PubMed]

126. Liao, T.-Y.; Easton, C.D.; Thissen, H.; Tsai, W.-B. Aminomalononitrile-Assisted Multifunctional Antibacterial Coatings. ACS Biomater. Sci. Eng. 2020, 6, 3349-3360. [CrossRef]

127. Jung, J.; Menzies, D.J.; Thissen, H.; Easton, C.D.; Evans, R.A.; Henry, R.; Deletic, A.; McCarthy, D.T. New Prebiotic Chemistry Inspired Filter Media for Stormwater/Greywater Disinfection. J. Hazard. Mater. 2019, 378, 120749. [CrossRef] [PubMed]

128. Ball, V. Antioxidant Activity of Films Inspired by Prebiotic Chemistry. Mater. Lett. 2021, 285, 129050. [CrossRef]

129. Minard, R.D.; Hatcher, P.G.; Gourley, R.C.; Matthews, C.N. Structural Investigations of Hydrogen Cyanide Polymers: New Insights Using TMAH Thermochemolysis/GC-MS. Orig. Life Evol. Biosph. 1998, 28, 461-473. [CrossRef] [PubMed]

130. Ferris, J.P.; Donner, D.B.; Lobo, A.P. Possible Role of Hydrogen Cyanide in Chemical Evolution: Investigation of the Proposed Direct Synthesis of Peptides from Hydrogen Cyanide. J. Mol. Biol. 1973, 74, 499-510. [CrossRef]

131. Mizutani, H.; Mikuni, H.; Takahasi, M.; Noda, H. Study on the Photochemical Reaction of HCN and Its Polymer Products Relating to Primary Chemical Evolution. Orig. Life Evol. Biosph. 1975, 6, 513-525. [CrossRef] [PubMed]

132. Draganić, Z.D.; Niketić, V.; Jovanović, S.; Draganić, I.G. The Radiolysis of Aqueous Ammonium Cyanide: Compounds of Interest to Chemical Evolution Studies. J. Mol. Evol. 1980, 15, 239-260. [CrossRef]

133. Niketić, V.; Draganić, Z.D.; Nešković, S.; Jovanović, S.; Draganić, I.G. Radiolysis of Aqueous Solutions of Hydrogen Cyanide (pH 6): Compounds of Interest in Chemical Evolution Studies. J. Mol. Evol. 1983, 19, 184-191. [CrossRef]

134. Vujošević, S.I.; Negrón-Mendoza, A.; Draganić, Z.D. Radiation-Induced Polymerization in Dilute Aqueous Solutions of Cyanides. Orig. Life Evol. Biosph. 1990, 20, 49-54. [CrossRef]

135. Marín-Yaseli, M.R.; Cid, C.; Yagüe, A.I.; Ruiz-Bermejo, M. Detection of Macromolecular Fractions in HCN Polymers Using Electrophoretic and Ultrafiltration Techniques. Chem. Biodiver. 2017, 14, e1600241. [CrossRef] [PubMed]

136. Bonnet, J.-Y.; Thissen, R.; Frisari, M.; Vuitton, V.; Quirico, É.; Orthous-Daunay, F.-R.; Dutuit, O.; Le Roy, L.; Fray, N.; Cottin, H.; et al. Compositional and Structural Investigation of HCN Polymer through High Resolution Mass Spectrometry. Int. J. Mass Spectrom. 2013, 354-355, 193-203. [CrossRef]

137. Fernández, A.; Ruiz-Bermejo, M.; De La Fuente, J.L. Modelling the Kinetics and Structural Property Evolution of a Versatile Reaction: Aqueous HCN Polymerization. Phys. Chem. Chem. Phys. 2018, 20, 17353-17366. [CrossRef] [PubMed]

138. Toh, R.J.; Evans, R.; Thissen, H.; Voelcker, N.H.; d'Ischia, M.; Ball, V. Deposition of Aminomalononitrile-Based Films: Kinetics, Chemistry, and Morphology. Langmuir 2019, 35, 9896-9903. [CrossRef]

139. de la Fuente, J.L.; Ruiz-Bermejo, M.; Nna-Mvondo, D.; Minard, R.D. Further Progress into the Thermal Characterization of HCN Polymers. Polym. Degrad. Stab. 2014, 110, 241-251. [CrossRef]

140. Ruiz-Bermejo, M.; de la Fuente, J.L.; Marín-Yaseli, M.R. The Influence of Reaction Conditions in Aqueous HCN Polymerization on the Polymer Thermal Degradation Properties. J. Anal. Appl. Pyrolysis 2017, 124, 103-112. [CrossRef]

141. de la Fuente, J.L.; Ruiz-Bermejo, M.; Menor-Salván, C.; Osuna-Esteban, S. Thermal Characterization of HCN Polymers by TG-MS, TG, DTA and DSC Methods. Polym. Degrad. Stab. 2011, 96, 943-948. [CrossRef]

142. Cataldo, F.; Lilla, E.; Ursini, O.; Angelini, G. TGA-FT-IR Study of Pyrolysis of Poly(Hydrogen Cyanide) Synthesized from Thermal Decomposition of Formamide. Implications in Cometary Emissions. J. Anal. Appl. Pyrolysis 2010, 87, 34-44. [CrossRef]

143. Cruikshank, D.P.; Allamandola, L.J.; Hartmann, W.K.; Tholen, D.J.; Brown, R.H.; Matthews, C.N.; Bell, J.F. Solid C $\equiv N$ Bearing Material on Outer Solar System Bodies. Icarus 1991, 94, 345-353. [CrossRef]

144. Völker, T. Polymere Blausäure. Angew. Chem. 1960, 72, 379-384. [CrossRef]

145. Ruiz-Bermejo, M.; de la Fuente, J.L.; Rogero, C.; Menor-Salván, C.; Osuna-Esteban, S.; Martín-Gago, J.A. New Insights into the Characterization of 'Insoluble Black HCN Polymers'. Chem. Biodiver. 2012, 9, 25-40. [CrossRef]

146. Quirico, E.; Montagnac, G.; Lees, V.; McMillan, P.F.; Szopa, C.; Cernogora, G.; Rouzaud, J.-N.; Simon, P.; Bernard, J.-M.; Coll, P.; et al. New Experimental Constraints on the Composition and Structure of Tholins. Icarus 2008, 198, 218-231. [CrossRef]

147. Liebman, S.A.; Pesce-Rodriguez, R.A.; Matthews, C.N. Organic Analysis of Hydrogen Cyanide Polymers: Prebiotic and Extraterrestrial Chemistry. Adv. Space Res. 1995, 15, 71-80. [CrossRef]

148. Umemoto, K.; Takahasi, M.; Yokota, K. Studies on the Structure of HCN Oligomers. Orig. Life Evol. Biosph. 1987, 17, $283-293$. [CrossRef]

149. Sagan, C.; Khare, B.N. Tholins: Organic Chemistry of Interstellar Grains and Gas. Nature 1979, 277, 102-107. [CrossRef]

150. Khare, B.N.; Sagan, C.; Thompson, W.R.; Arakawa, E.T.; Suits, F.; Callcott, T.A.; Williams, M.W.; Shrader, S.; Ogino, H.; Willingham, T.O.; et al. The Organic Aerosols of Titan. Adv. Space Res. 1984, 4, 59-68. [CrossRef]

151. McDonald, G.D.; Khare, B.N.; Reid Thompson, W.; Sagan, C. $\mathrm{CH}_{4} / \mathrm{NH}_{3} / \mathrm{H}_{2} \mathrm{O}$ Spark Tholin: Chemical Analysis and Interaction with Jovian Aqueous Clouds. Icarus 1991, 94, 354-367. [CrossRef]

152. Matthews, C.N.; Ludicky, R. The Dark Nucleus of Comet Halley: Hydrogen Cyanide Polymers. In ESLAB Symposium on the Exploration of Halley's Comet; European Space Agency: Paris, France, 1986; Volume 250.

153. Coll, P.; Coscia, D.; Smith, N.; Gazeau, M.-C.; Ramirez, S.I.; Cernogora, G.; Israël, G.; Raulin, F. Experimental Laboratory Simulation of Titan's Atmosphere: Aerosols and Gas Phase. Planet. Space Sci. 1999, 47, 1331-1340. [CrossRef]

154. Sciamma-O'Brien, E.; Carrasco, N.; Szopa, C.; Buch, A.; Cernogora, G. Titan's Atmosphere: An Optimal Gas Mixture for Aerosol Production? Icarus 2010, 209, 704-714. [CrossRef] 
155. Ruiz-Bermejo, M.; Menor-Salván, C.; de la Fuente, J.L.; Mateo-Martí, E.; Osuna-Esteban, S.; Martín-Gago, J.Á.; VeintemillasVerdaguer, S. $\mathrm{CH}_{4} / \mathrm{N}_{2} / \mathrm{H}_{2}$-Spark Hydrophobic Tholins: A Systematic Approach to the Characterisation of Tholins. Part II. Icarus 2009, 204, 672-680. [CrossRef]

156. Cataldo, F.; Patanè, G.; Compagnini, G. Synthesis of HCN Polymer from Thermal Decomposition of Formamide. J. Macromol. Sci. Part A 2009, 46, 1039-1048. [CrossRef]

157. Ferris, J.P.; Edelson, E.H.; Auyeung, J.M.; Joshi, P.C. Structural Studies on HCN Oligomers. J. Mol. Evol. 1981, 17, 69-77. [CrossRef] [PubMed]

158. Garbow, J.R.; Schaefer, J.; Ludicky, R.; Matthews, C.N. Detection of Secondary Amides in Hydrogen Cyanide Polymers by Dipolar Rotational Spin-Echo Nitrogen- ${ }^{15}$ NMR. Macromolecules 1987, 20, 305-309. [CrossRef]

159. Matthews, C.N.; Ludicky, R.; Schaefer, J.; Stejskal, E.O.; McKay, R.A. Heteropolypeptides from Hydrogen Cyanide and Water? Solid State ${ }^{15} \mathrm{~N}$ NMR Investigations. Orig. Life Evol. Biosph. 1984, 14, 243-250. [CrossRef]

160. McKay, R.A.; Schaefer, J.; Stejskal, E.O.; Ludicky, R.; Matthews, C.N. Double-Cross-Polarization Detection of Labeled Chemical Bonds in Hydrogen Cyanide Polymerization. Macromolecules 1984, 17, 1124-1130. [CrossRef]

161. Mamajanov, I.; Herzfeld, J. HCN Polymers Characterized by Solid State NMR: Chains and Sheets Formed in the Neat Liquid. J. Chem. Phys. 2009, 130, 134503. [CrossRef]

162. Mamajanov, I.; Herzfeld, J. HCN Polymers Characterized by SSNMR: Solid State Reaction of Crystalline Tetramer (Diaminomaleonitrile). J. Chem. Phys. 2009, 130, 134504. [CrossRef]

163. Eastman, M.P.; Helfrich, F.S.E.; Umantsev, A.; Porter, T.L.; Weber, R. Exploring the Structure of a Hydrogen Cyanide Polymer by Electron Spin Resonance and Scanning Force Microscopy. Scanning 2003, 25, 19-24. [CrossRef]

164. Marín-Yaseli, M.R.; Moreno, M.; de la Fuente, J.L.; Briones, C.; Ruiz-Bermejo, M. Experimental Conditions Affecting the Kinetics of Aqueous HCN Polymerization as Revealed by UV-Vis Spectroscopy. Acta Part A Mol. Biomol. Spectrosc. 2018, 191, 389-397. [CrossRef] [PubMed]

165. Ferris, J.P.; Edelson, E.H. Chemical Evolution. Mechanism of the Condensation of Cyanide to Hydrogen Cyanide Oligomers. J. Org. Chem. 1978, 43, 3989-3995. [CrossRef]

166. Cataldo, F. Concerning the Chemical Structure of the Dicyanogen Photopolymer and Its Presence in Certain Bodies of the Solar System. Implications on the Synthesis of Some Prebiotic Molecules. Int. J. Astrobiol. 2002, 1, 25-30. [CrossRef]

167. Mas, I.; Hortelano, C.; Ruiz-Bermejo, M.; de la Fuente, J.L. Highly Efficient Melt Polymerization of Diaminomaleonitrile. Eur. Polym. J. 2021, 143, 110185. [CrossRef]

168. Nandi, S.; Bhattacharyya, D.; Anoop, A. Prebiotic Chemistry of HCN Tetramerization by Automated Reaction Search. Chem. Eur. J. 2018, 24, 4885-4894. [CrossRef]

169. Andersen, J.L.; Andersen, T.; Flamm, C.; Hanczyc, M.M.; Merkle, D.; Stadler, P.F. Navigating the Chemical Space of HCN Polymerization and Hydrolysis: Guiding Graph Grammars by Mass Spectrometry Data. Entropy 2013, 15, 4066-4083. [CrossRef]

170. Choe, J.C. Water-Assisted Dimerization of Hydrogen Cyanide: A Computational Study. Bull. Korean Chem. Soc. 2017, 38, 1531-1533. [CrossRef]

171. Kua, J.; Thrush, K.L. HCN, Formamidic Acid, and Formamide in Aqueous Solution: A Free-Energy Map. J. Phys. Chem. B 2016, 120, 8175-8185. [CrossRef]

172. Choe, J.C. Dimerization of HCN in Interstellar Icy Grain Mantles: A DFT Study. Bull. Korean Chem. Soc. 2019, 40, 205-206. [CrossRef]

173. Glaser, R.; Hodgen, B.; Farrelly, D.; McKee, E. Adenine Synthesis in Interstellar Space: Mechanisms of Prebiotic Pyrimidine-Ring Formation of Monocyclic HCN-Pentamers. Astrobiology 2007, 7, 455-470. [CrossRef] [PubMed]

174. Smith, I.W.M.; Talbi, D.; Herbst, E. The Production of HCN Dimer and More Complex Oligomers in Dense Interstellar Clouds. Astron. Astrophys. 2001, 369, 611-615. [CrossRef]

175. Kikuchi, O.; Watanabe, T.; Satoh, Y.; Inadomi, Y. Ab Initio GB Study of Prebiotic Synthesis of Purine Precursors from Aqueous Hydrogen Cyanide: Dimerization Reaction of HCN in Aqueous Solution. J. Mol. Struct. THEOCHEM 2000, 507, 53-62. [CrossRef]

176. Yim, M.K.; Choe, J.C. Dimerization of HCN in the Gas Phase: A Theoretical Mechanistic Study. Chem. Phys. Lett. 2012, 538, 24-28. [CrossRef]

177. Lee, H.M.; Choe, J.C. Formation of Glycine from HCN and H2O: A Computational Mechanistic Study. Chem. Phys. Lett. 2017, 675, 6-10. [CrossRef]

178. Roy, D.; Najafian, K.; von R. Schleyer, P. Chemical Evolution: The Mechanism of the Formation of Adenine under Prebiotic Conditions. Proc. Natl. Acad. Sci. USA 2007, 104, 17272-17277. [CrossRef]

179. Guo Hong, S.; Qu, X.; Yuan Fu, X. A Quantum Chemical Study on the Mechanism of HCN Oligomerization. J. Mol. Struct. THEOCHEM 1992, 257, 25-32. [CrossRef]

180. Kofranek, M.; Karpfen, A.; Lischka, H. Ab Initio Studies on Hydrogen-Bonded Clusters. I. Linear and Cyclic Oligomers of Hydrogen Cyanide. Chem. Phys. 1987, 113, 53-64. [CrossRef]

181. Bochvar, D.A.; Nikerov, M.V.; Stankevich, I.V. A CNDO/2 Study of the Relative Stability of Several Hydrogen Cyanide Oligomers $(\mathrm{HCN})_{\mathrm{x}}$. J. Struct. Chem. 1984, 24, 621-622. [CrossRef]

182. Hall, H.K.; Padias, A.B.; Kamachi, M.; Hashidzume, A. Synthesis and Polymerizability of C $\equiv$ N Monomers. J. Polym. Sci. Part A Polym. Chem. 2012, 50, 3467-3474. [CrossRef]

183. Dalton, S.; Heatley, F.; Budd, P.M. Thermal Stabilization of Polyacrylonitrile Fibres. Polymer 1999, 40, 5531-5543. [CrossRef] 
184. De Vries, L. Stable Glycinonitrile Radical. Evidence Suggesting Generation of Aminocyanocarbenes from Aminomalonitriles in Basic Media. J. Org. Chem. 1973, 38, 2604-2613. [CrossRef]

185. De Vries, L. Thermal Transformations of an Aminomalononitrile and of an Aminocyanoketenimine. Evidence for Homolysis and Heterolysis and for Aminocyanocarbenes. J. Org. Chem. 1973, 38, 4357-4362. [CrossRef]

186. Sruthi, P.R.; Anas, S. An Overview of Synthetic Modification of Nitrile Group in Polymers and Applications. J. Polym. Sci. 2020, 58, 1039-1061. [CrossRef]

187. Wöuhrle, D.; Knothe, G. Polymers from Nitriles. VII. Polymerization of Fumaronitrile with Triethylamine as Initiator. J. Polym. Sci. Part A Polym. Chem. 1988, 26, 2435-2447. [CrossRef]

188. Padias, A.B.; Hall, H.K. Semiconducting Polymers via the High Temperature Free Radical Polymerization of Multinitriles. J. Polym. Sci. Part A Polym. Chem. 1986, 24, 1675-1683. [CrossRef]

189. Liu, Y.; Qin, A.; Tang, B.Z. Polymerizations Based on Triple-Bond Building Blocks. Prog. Polym. Sci. 2018, 78, 92-138. [CrossRef]

190. Miller, T.S.; Jorge, A.B.; Suter, T.M.; Sella, A.; Corà, F.; McMillan, P.F. Carbon Nitrides: Synthesis and Characterization of a New Class of Functional Materials. Phys. Chem. Chem. Phys. 2017, 19, 15613-15638. [CrossRef] [PubMed]

191. Gao, C.; Yan, D. Hyperbranched Polymers: From Synthesis to Applications. Prog. Polym. Sci. 2004, 29, 183-275. [CrossRef]

192. Amal, A.-A. Recent Developments in the Chemistry of Diaminomaleonitrile. Curr. Org. Synth. 2015, 12, 110. [CrossRef]

193. Johnson, D.M.; Reybuck, S.E.; Lawton, R.G.; Rasmussen, P.G. Condensation of DAMN with Conjugated Aldehydes and Polymerizations of the Corresponding Imines. Macromolecules 2005, 38, 3615-3621. [CrossRef]

194. Aruna; Rani, B.; Swami, S.; Agarwala, A.; Behera, D.; Shrivastava, R. Recent Progress in Development of 2,3-Diaminomaleonitrile (DAMN) Based Chemosensors for Sensing of Ionic and Reactive Oxygen Species. RSC Adv. 2019, 9, 30599-30614. [CrossRef]

195. Thissen, H.; Evans, R.A.; Koegler, A. Hydrogen Cyanide-Based Polymer Surface Coatings and Hydrogels. U.S. Patent 2015/0140660 A, 21 May 2015.

196. Chung, K.K.; Fechler, N.; Patrini, M.; Galinetto, P.; Comoretto, D.; Antonietti, M. High Definition Conductive Carbon Films from Solution Processing of Nitrogen-Containing Oligomers. Carbon 2015, 94, 1044-1051. [CrossRef]

197. Hall, H.K.; Padias, A.B. Organic and Polymer Chemistry of Electrophilic Tri- and Tetrasubstituted Ethylenes. J. Polym. Sci. Part A Polym. Chem. 2004, 42, 2845-2858. [CrossRef]

198. Ozimiński, W.P.; Dobrowolski, J.C.; Mazurek, A.P. DFT Studies on Tautomerism of C5-Substituted 1,2,4-Triazoles. J. Mol. Struct. THEOCHEM 2004, 680, 107-115. [CrossRef]

199. Dines, T.J.; Onoh, H. An Infrared and Resonance Raman Spectroscopic Study of Phenylazonaphthol Pigments. Spectrochim. Acta Part A Mol. Biomol. Spectrosc. 2006, 64, 891-900. [CrossRef] [PubMed]

200. Derradji, M.; Wang, J.; Liu, W. 2-Phthalonitrile Resins' Properties. In Phthalonitrile Resins and Composites; Derradji, M., Wang, J., Liu, W., Eds.; Plastics Design Library; William Andrew Publishing: Amsterdam, The Netherlands, 2018; pp. 55-106. [CrossRef]

201. Li, Y.; Chen, Q.; Xu, T.; Xie, Z.; Liu, J.; Yu, X.; Ma, S.; Qin, T.; Chen, L. De Novo Design and Facile Synthesis of 2D Covalent Organic Frameworks: A Two-in-One Strategy. J. Am. Chem. Soc. 2019, 141, 13822-13828. [CrossRef] [PubMed] 